\title{
The Molecular, Cellular and Clinical Consequences of Targeting the Estrogen Receptor Following Estrogen Deprivation Therapy
}

\author{
Ping Fan ${ }^{1} *$, Philipp Y. Maximov ${ }^{1}$, Ramona F. Curpan ${ }^{2}$, Balkees \\ Abderrahman $^{3}$, and V. Craig Jordan ${ }^{1}$ \\ ${ }^{1}$ MD Anderson Cancer Center, Department of Breast Medical Oncology, Houston, TX, USA. \\ ${ }^{2}$ Institute of Chemistry, Romanian Academy, Timisoara, Romania. \\ ${ }^{3}$ The University of Jordan, Faculty of Medicine, Amman, Hashemite Kingdom of Jordan. \\ * Equal contribution
}

\author{
Corresponding Author: \\ V. Craig Jordan OBE, PhD, DSc, FMedSci \\ University of Texas, MD Anderson Cancer Center, \\ Department of Breast Medical Oncology, \\ 1515 Holcombe Blvd., Unit 1354 \\ Houston, Texas 77030 \\ Tel: +1(713)792-2121 \\ E-mail: VCJordan@mdanderson.org
}




\begin{abstract}
During the past twenty years our understanding of the control of breast tumor development, growth and survival has changed dramatically. The once long forgotten application of high dose synthetic estrogen therapy as the first chemical therapy to treat any cancer has been resurrected, refined and reinvented as the new biology of estrogen-induced apoptosis. High dose estrogen therapy was cast aside once tamoxifen, from its origins as a failed "morning after pill", was reinvented as the first targeted therapy to treat any cancer. The current understanding of the mechanism of estrogen-induced apoptosis is described as a consequence of acquired resistance to long term antihormone therapy in estrogen receptor (ER) positive breast cancer. The ER signal transduction pathway remains a target for therapy in breast cancer despite "antiestrogen" resistance, but becomes a regulator of resistance. Multiple mechanisms of resistance come into play: Selective ER Modulator (SERM) stimulated growth, growth factor/ER crosstalk, estrogeninduced apoptosis and mutations of ER. But it is with the science of estrogen-induced apoptosis that the next innovation in women's health will be developed. Recent evidence suggests that the glucocorticoid properties of medroxyprogesterone acetate blunt estrogen-induced apoptosis in estrogen deprived breast cancer cell populations. As a result breast cancer develops during longterm Hormone Replacement Therapy (HRT). A new synthetic progestin with estrogen-like properties, such as the 19 nortestosterone derivatives used in oral contraceptives, will continue to protect the uterus from unopposed estrogen stimulation but at the same time, reinforce apoptosis in vulnerable populations of nascent breast cancer cells.
\end{abstract}


"As most breast cancers are ER positive and given the worldwide prevalence of the disease, it is arguable that anti-estrogen treatments have had greater global impact than any other treatment intervention in cancer medicine." (Sledge et al., 2014)

"The development of therapeutics for ER-expressing breast cancer has been one of the great clinical advances of the past 50 years and has served as a paradigm for the development of targeted therapies in oncology." (Sledge et al., 2014)

\section{INTRODUCTION}

Breast cancer has the unfortunate distinction of being the cancer with the highest incidence of all disease sites in women. Annual incidence statistics in the United States of America are 92.93 cases per 100,000 women, United Kingdom 94.99, Brazil 59.46, Russia 45.64 and China 22.07 (CancerResearchUK.org). It is estimated that, each year there are a million new cases of breast cancer worldwide. Until forty years ago, breast cancer also had the unfortunate distinction of having the highest death rate, but two things changed. Firstly, lung cancer death rates overtook breast cancer as the leading cause of cancer death in women; as the result of new generations of women embracing cigarette smoking. Secondly, at this time, a new targeted approach to breast cancer therapy was conceived. This approach was translated, through animal models to clinical trials and is now the standard of care (Jordan, 2015a).

The new successful approach was not, as anticipated, combination cytotoxic chemotherapy that was showing enormous promise in the 1970's as a curative strategy for breast cancer. This optimism for cytotoxic chemotherapy followed close on the heels of advances in the cure of childhood leukemia and Hodgkin's disease. If the correct scheduling of a lexicon of cytotoxic agents could be discovered, cures would then emerge and be amplified by agents with different mechanisms of action. This "logical" approach of combining non-specific agents with different mechanisms of action was planned to retard the development of drug resistance; a 
principle revisited in medical oncology today by simultaneously blocking cell survival pathways with precision targeting.

By contrast, the key to success of the new strategy to treat breast cancer was to emerge, strangely enough, from the fashion of medical research in the 1960's, reproductive endocrinology which was hot on the heels of the triumph of oral contraception that changed society forever. The goal in industry was to find new contraceptive approaches to expand the market. The new knowledge of "morning after pills" acquired during the reproductive revolution that started but then failed, provided the new tools and targets to address the new medical challenge. The "War on Cancer" was declared on December 23, 1971 and signed into law by President of the United States Richard M. Nixon as the National Cancer Act. Henceforth, the translation of new treatment ideas from clinical cancer centers would be propelled into clinical testing through cooperative cancer clinical trial groups. The successful treatment strategy in this process would emerge as the unexpected silent kill of cancer cells with few of the onerous life threatening side effects of cytotoxic chemotherapy. The battle to defeat breast cancer with combination cytotoxic chemotherapy was, indeed, a fight to the death worthy of a war on cancer, whereas the new approach of targeting the estrogen receptor (ER) in breast cancer (Jensen and Jordan, 2003) turned out to be a stealth campaign. This heralded a new campaign in the war on cancer with clinical strategies in breast cancer of long-term adjuvant treatment and chemoprevention (Jordan, 2008a). The era of this therapeutic change (1970-2000), with countless lives saved or improved, would create the current era of molecular targeted medicine (Sledge et al., 2014) with the current promise that the power of molecular biology will solve the riddle of tumor complexity for the individual and neutralize the machinery of tumor growth. Precision interdiction promises to block off tumor survival routes. An attack at one moment in 
time in the evolution of tumor plasticity is planned and predicted to eradicate cancer and cure the patient. The key to success will be, as it has always been, which moment in time?

To appreciate the development of the new strategy of the targeted treatment of breast cancer, it is necessary to understand the process by which the pieces of the puzzle of hormonedependent breast cancer were organized and arranged to derive the modern basis to treat breast cancer rationally. As in all human achievement, the process is based on individuals, serendipity, competition, trial and error, determination and fashions in research.

Reproductive endocrinology slowly underwent a metamorphosis in the early 1970's to become translational breast cancer research. That is where Federal funding now focused with the National Cancer Act. However, the process of change with cancer surgery and therapeutics started long before through clinical observation, trial and error. The first concrete clues that metastatic breast cancer was in some way regulated by the ovary occurred when Stanley Boyd at Charing Cross Hospital combined and analyzed all the available data on the outcomes of oophorectomy for metastatic breast cancer in Britain (Boyd, 1900). A case report published by George Beatson (Beatson, 1896), triggered considerable interest in the possibility of tumor regressions following oophorectomy. Unfortunately, successful tumor regression, in the main, was short lived, but Boyd found a 30\% response rate for endocrine ablation (Boyd, 1900). This $1 / 3$ response rate has remained consistent for a century for any kind of endocrine therapy. However, the question to be addressed in the first half of the $20^{\text {th }}$ century was: "which tumors would respond and which tumors would not?"

Laboratory studies in high incidence strains of mice with mammary cancer found that the ovary was necessary for tumorigenesis (Lathrop and Loeb, 1916). Subsequent work by Allen and Doisy (Allen and Doisy, 1923) identified estrogen as the principal hormone involved in the 
sexual cycle of animals, but Lacassagne took one further step by linking estrogen with mammary carcinogenesis (Lacassagne, 1936b,Lacassagne, 1936a). But just as the puzzle of breast carcinogenesis and regulation was being clarified, Alexander Haddow demonstrated that high dose synthetic estrogen actually could also cause breast cancer regression in postmenopausal women (Haddow et al., 1944). So, breast cancer regressed with estrogen withdrawal following oophorectomy in premenopausal patients but high dose synthetic estrogens caused regression of breast cancer in postmenopausal women. It was a paradox that has taken more than sixty years to resolve but it is now understood (Jordan, 2008b).

The solution of the Haddow paradox in breast cancer again required the tools of endocrinology that were marshalled by academia and industry to establish an infrastructure to conceive the hormonal regulation of the menstrual cycle at the Worcester Foundation for Experimental Biology (the home of the oral contraceptive) (Speroff, 2009) and the incentive for industry to create orally active synthetic steroids to deliver hormones regularly and safely (Laboratorios Syntex SA (Mexico City, Mexico) and GD Searle \& Co. (Skokie, IL)). The oral contraceptive was born in the 1950's and 60's.

The first clues to the target site specificity of estrogens in estrogen target tissues (uterus, vagina, pituitary gland) around the female body, were documented using $\left[{ }^{3} \mathrm{H}\right]$ labeled estrogens in animals (Glascock and Hoekstra, 1959,Jensen and Jacobson, 1962). Estrogen target tissues bound and retained $\left[{ }^{3} \mathrm{H}\right]$ estrogens, but non-target tissues (heart, colon) did not. These data resulted in early clinical applications (Folca et al., 1961,Jensen et al., 1971) to predict the outcome of endocrine ablation therapy in metastatic breast cancer (McGuire et al., 1975). The isolation and quantitation of the estrogen receptor (ER) in target tissues answered the question: "Why do some tumors respond to oophorectomy?" (McGuire et al., 1975) The clinical ER 
laboratory assay was created in the mid 1970's to establish whether estrogen ablative therapy was to be of value for a patient with metastatic breast cancer. The results were clear: if the tumor sample contained ER then there was a high probability (60-70\%) that objective tumor regression would occur; if there was little ( $<10$ femtomoles/mg of cytosol protein) or none there was little prospect of a response (<10\%) (Jordan et al., 1988,McGuire et al., 1975). The extraction, isolation, and biochemical description of the ER protein answered the question: "How estradiol $\left(\mathrm{E}_{2}\right)$ could specifically stimulate an estrogen target tissue?" (Toft and Gorski, 1966,Toft et al., 1967)

The way forward to treat breast cancer followed an unlikely path in reproductive endocrinology and pharmacology. Nevertheless, the personal path and serendipity became critical for the development of the first targeted drug in cancer treatment. The chance discovery of the first nonsteroidal antiestrogen MER25 and the finding that it was an effective postcoital contraceptive in rats, triggered an enormous interest in the pharmaceutical industry to develop a "morning after" pill (Lerner and Jordan, 1990). Regrettably for reproductive endocrinologists, the clinical trials actually demonstrated the opposite effect; both, the pioneer clomiphene and the improved tamoxifen (Fig. 1), induced ovulation (Lerner and Jordan, 1990). This was fortunate for breast cancer therapy, but the way ahead was met with indifference (Jordan, 2003c,Jordan, 2006,Maximov et al., 2013a) as all hopes and predictions were that cytotoxic chemotherapy would cure breast cancer.

The treatment of metastatic breast cancer with antiestrogens in postmenopausal women was an obvious choice as a palliative therapy, but all antiestrogens tested in small trials were abandoned either because of unacceptable toxicities, but mainly because of unacceptably low profit projections (Jordan, 2006,Lerner and Jordan, 1990). Tamoxifen was resurrected only by 
chance (Jordan, 2006) and through the use of prescient animal models (Jordan, 2015a) to become the first successful therapy, targeted to the tumor ER, for the treatment and prevention of breast cancer (Jordan, 2003c).

Remarkably, the path to progress did not end with tamoxifen; tamoxifen was a beginning of three decades of targeted innovation in endocrine therapeutics. Tamoxifen is not a complete or pure antiestrogen, but has an intrinsic estrogenicity, a property that was argued could lead to acquired drug resistance or incomplete responses at the tumor ER during treatment. The study of the pharmacology of tamoxifen led first to the target site specific actions of this "non-steroidal antiestrogen" that had the ability to block estrogen-stimulated tumor growth via the ER, but the same ER at different sites also maintained bone density and lowered circulating cholesterol. The tamoxifen ER complex could turn on and turn off estrogen target sites around a patient's body (Jordan, 2001). Although there were potential beneficial effects for women, laboratory research with tamoxifen demonstrated the target site specific actions for breast cancer and endometrial cancer. Human endometrial cancer could be stimulated to grow in immune deficient animals with the simultaneous blockade of breast cancer growth (Gottardis et al., 1988). This observation rapidly translated to clinical care and changed clinical practice (Fornander et al., 1989,Hardell, 1988,Jordan, 1988b). Gynecologists were involved, for the first time, as members of the breast cancer treatment team.

However, the pharmacology of tamoxifen introduced a new dimension in therapeutics and resulted in Selective ER Modulators (SERMs) with better safety profiles. Raloxifene (Fig. 1) was the result. This is the first true SERM that treats and prevents osteoporosis, but prevents breast cancer at the same time (Cummings et al., 1999). The key to success is long-term therapy. A goal now by the pharmaceutical industry, was to seek different SERMs to treat multiple 
diseases in women: osteoporosis, coronary heart disease, strokes, hot flashes, dyspareunia as well as breast cancer prevention but with endometrial safety. This goal is being achieved (Maximov et al., 2013b).

Tamoxifen's clinical success in breast cancer, but with some estrogen-like actions, stimulated another innovation in the 1970's. Drs. Angela and Harry Brodie, working initially at the Worcester Foundation, at the same time as the first clinical studies with tamoxifen were being conducted (Jordan and Brodie, 2007), created a second targeted therapy to treat breast cancer. This time the target was the aromatase enzyme system that synthesizes estrogens out of precursor androgens in the body fat of postmenopausal patients. Dr. Angela Brodide's innovation and persistence to discover and develop a precisely targeted aromatase inhibitor (AI) (Coombes et al., 1984) stimulated the pharmaceutical industry to create a new family of AIs (Santen et al., 2009) because now there was a huge market to capture if the compounds, as predicted, would be both effective and safer than tamoxifen. The idea that "No estrogen was better than any antiestrogenic drug" was born and clinical trials showed this to be true (Dowsett et al., 2010) (as a comment; the so called "pure" antiestrogen fulvestrant (Wakeling et al., 1991), which destroys the ER is making a comeback (Di Leo et al., 2014,). The success of both tamoxifen and aromatase inhibitors as therapy for breast cancer, has resulted in benefit for millions of women over the past 4 decades. The challenge now is to build on success. Knowledge derived from laboratory research and clinical samples hold the promise that new approaches to prevent acquired drug resistance can be integrated into the clinical treatment plan.

In this review we will address the advances that have occurred over the past decade in our understanding of the ER signal transduction pathway as the driver for growth in an estrogen containing environment to maintain cell population expansion, and the principal signal 
transduction pathway to guide breast cancer cell selection under conditions of estrogen deprivation with SERMs or AIs.

\section{ESTROGEN RECEPTORS}

Understanding the action of targeted antiestrogenic therapy for ER-positive breast cancer is dependent upon the evolving characterization of estrogen-stimulated growth. The gene encoding the ER was cloned (Greene et al., 1986, Walter et al., 1985) and was named ESR1. The protein was renamed as ER $\alpha$ as a second type of ER was discovered 10 years later and was named ER $\beta$ (Kuiper et al., 1996). The ERs now belong to the nuclear hormone receptor superfamily and bind estrogens and antiestrogens to regulate transcription of estrogen-responsive target genes. Since the role of the ER $\beta$ in breast cancer in not well defined (Haldosen et al., 2014) and is not a target for hormonal cancer therapy, we will concentrate, in this report, on ER $\alpha$, and thus simply referred to it as the ER.

The ESR1 gene is located on chromosome 6q25.1 and encodes a 595 aminoacids, 66kDa protein. The protein consists of 6 domains labeled A-F (Kumar et al., 1987) (Fig. 2). The A/B domains are in the $\mathrm{N}$-terminal region of the protein and contain a ligand-independent and transcriptionally minor activating function region, called AF-1. Domain C contains the zincfinger DNA-binding region that is responsible for binding to the Estrogen Response Elements (EREs) in the promoters of target genes. The D domain contains a signal region necessary for the nuclear localization of the protein and acts a hinge to the $\mathrm{C}$ domain. The $\mathrm{E}$ domain is the Ligand Binding Domain (LBD). The LBD consists of $12 \alpha$ helices, where helices H3-12 form a ligandbinding cavity and H12 acts as a "lid" for the ligand, once it is bound to the receptor. The E domain also contains a major transcription activation region called AF-2 and is necessary for the recruitment of co-activators via an LXXLL-motif. The C-terminal domain is called the F domain 
and appears to modulate the functions of the ER in a ligand, promoter and cell specific fashion (Koide et al., 2007,Montano et al., 1995,Schwartz et al., 2002,Yang et al., 2008). The ER protein is localized in the nucleus of the cell and when not bound with a ligand, it is complexed with Heat Shock Proteins (HSPs). Once the ER is bound with an agonist, the ER:HSP complex disassociates and forms a homodimer complex. The LBD of the receptor undergoes a conformational change with $\mathrm{H} 12$ sealing the ligand in the cavity and thus allowing the coactivators (such as steroid receptor coactivators (SRCs)) to be recruited at the surface of the ER protein. Activated ER bound with coactivators is able to further recruit other transcriptional factors which is necessary for gene transcription (McKenna and O'Malley, 2002). Activated ER homodimer complex then binds to the promoter regions containing the EREs of the estrogenresponsive genes and activates their transcription (Sanchez et al., 2002). EREs are inverted palindromic 15 base pair repeat consensus sequences (Klinge, 2001). However, besides ERE binding, the ER can also exert its transcriptional action through other factors, such as Fos/Jun (AP-1 elements), or SP-1 (GC-rich SP-1 motifs) and influence transcription of genes promoters which do not have EREs ("tethered mechanism"). The ER can also inhibit transcription through the interaction with $\mathrm{NF}-\kappa \mathrm{B}$ (Kalaitzidis and Gilmore, 2005). Additionally, the ER can be regulated by phosphorylation of selected sites in a ligand-dependent (Lannigan, 2003) or independent manner (Feng et al., 2001). Transcriptional activity of the ER can be increased or decreased or even alter the localization of the protein itself depending on the location of the phosphorylation sites.

With this functional background of the ER protein regions, it is now appropriate to segway into the role of the ligand, to alter the shape of the ligand ER complex that then programs the cellular outcomes in this critical signal transduction pathway. 


\section{A MOLECULAR MODEL OF ESTROGEN/ANTIESTROGEN ACTION}

Studies in vitro during the early 1980's examined the structure-activity relationships (SAR) of ligands that bind to the ER and either activate (estrogens) or block (antiestrogens) $\mathrm{E}_{2}$ action at a model target gene (prolactin) in primary cultures of dispersed pituitary gland cells from weanling female rats. This approach had two major advantages: 1) studies in vivo to that point could not accurately determine whether an injected compound was metabolically transformed prior to action at an estrogen target tissue and 2) the pharmacokinetics of a ligand in vivo will affect pharmacodynamics at the estrogen target tissue. The changing concentrations at the ER in vivo, based on different blood clearance rates of ligands, will alter gene activation. Studies in vitro reflect constant concentrations to create knowledge of intrinsic efficacy of the complex specifically. The modulation of the prolactin gene through rigorous SAR (Jordan et al., 1984,Jordan et al., 1986,Jordan, 1987,Jordan and Koch, 1989,Lieberman et al., 1983a,Lieberman et al., 1983b,Robinson et al., 1988,Tate et al., 1984b) created the "crocodile model" of antiestrogen action (Jordan, 1987) with the antiestrogenic side chain predicted to interact at an "antiestrogenic region" of the ligand-binding domain. The side chain prevented the "jaws" closing over the ligand thereby preventing activation of the ER complex (Jordan, 1984,Lieberman et al., 1983b, Tate et al., 1984a).

Another assay system, that emerged subsequently, depended upon the modulation of estrogen-stimulated growth of ER-positive breast cancer cells in vitro (Murphy et al., 1990,Murphy et al., 1991). The assay was suitable for SAR studies in breast cancer therapeutics once appropriate assay conditions had been established (Berthois et al., 1986). The hypothetical molecular models from both the prolactin and cell replication assays were enhanced with precise molecular data once the ER was sequenced and could be manipulated (Greene et al., 
1986, Walter et al., 1985). This was essential to create precise molecular models once the X-ray crystallography of the purified LBD of the ER liganded either with estrogens or antiestrogens (Brzozowski et al., 1997,Shiau et al., 1998) was resolved more than a decade later.

The strength of the cellular assays to study SAR is the advantage of being a dynamic assay with a "real world" endpoint, whereas the partial resolution of the X-ray crystallography of the ER LBD with an estrogen or an antiestrogen is a snapshot of one moment in time. Nevertheless, despite the deficits in each analytical assay techniques new knowledge was accumulated by: 1) contributions from the McDonnell laboratory focused on the external surface of the SERM:ER complex (Chang et al., 1999,Huang et al., 2002,Norris et al., 1999), 2) the development of engineered cell systems to interrogate SERM:ER complexes and the modulation of gene function (Catherino et al., 1995,Jeng et al., 1994,Jiang and Jordan, 1992,Levenson et al., 1997,Levenson et al., 1998,Levenson and Jordan, 1998,Liu et al., 2002,MacGregor Schafer et al., 2000,MacGregor Schafer et al., 2001,Schafer et al., 1999) and 3) the discovery of a new dimension in SERM action modulated by co-regulator molecules (Jordan and O'Malley, 2007,Lonard et al., 2004,Onate et al., 1995). The integrated model for the mechanism of subcellular action of SERMs is illustrated in Fig. 3. SAR for estrogen-stimulated growth is currently of great importance to understand the mechanics of antihormone drug resistance through mutations of the unliganded receptor (see "Mutations of the ER" section) and also relevant to understand the modulation of estrogen-induced apoptosis in acquired resistance to estrogen deprivation (Jordan, 2008b). We will consider this aspect next.

The SAR of estrogen-induced cell replication have been compared and contrasted with the SAR for estrogen-induced apoptosis modulated by the ER (Maximov et al., 2010,Maximov et al., 2011,Maximov et al., 2014,Obiorah et al., 2014a,Obiorah and Jordan, 2014,Sengupta et 
al., 2013). The principal conclusions relative to the ER is that the traditional antiestrogens (4hydroxytamoxifen (4OHT), raloxifene and endoxifene) all block estrogen-induced apoptosis, but the triphenylethylene (TPE)-based angular estrogens cause a conformational change in the ER complex, where the TPE initially prefers to bind to an "antiestrogenic conformation" of the ER complex. The cellular dynamics, however, reveal that this is not a stable state but only delays the apoptotic process (Maximov et al., 2011,Obiorah et al., 2014a). The actual conformational states of the estrogenic and antiestrogenic LBDs will now be illustrated as a guide to future consideration of mutations in the ER in "Mutations of the ER" section. The snap shot reality of the crystal structures will be compared and contrasted with the hypothetical "crocodile model" derived from the dynamic prolactin gene/cell culture assay, and the subsequent work in interrogating the SERM:ER complex in engineered cell systems using a transforming growth factor alpha (TGF $\alpha$ ) target (Levenson et al., 1997,Liu et al., 2002,MacGregor Schafer et al., 2001). In the "crocodile model" the affinity of the ligand was controlled by a high affinity binding sites (HABS) in the unstructured LBD that is essential for the 3 phenolic hydroxyl of $\mathrm{E}_{2}$ to first locate the LBD and then for the steroid to create a scaffold around which the ER folds to enclose the steroid. This maneuver was predicted to activate the complex prior to the initiation of signal transduction (Jordan, 1984). The 3 phenolic hydroxyl of the planar steroid $\mathrm{E}_{2}$ (Fig. 1) is now known to be located and initially secured in the LBD of the ER by Glu353 and Arg394 (Fig. 4A) based on the X-ray crystallography (Brzozowski et al., 1997). The $17 \beta$ alcoholic hydroxyl anchors the steroid at His524 thereby allowing Helix 12 to seal the LBD (Fig. 4A). The amino acids Tyr537 and Asp538 are exposed externally as illustrated in the external view of the $\mathrm{E}_{2}: \mathrm{ER}$ complex (Fig. 4B) and appear to be closely aligned with Asp351 in the LBD. The SERMs raloxifene (Fig. 4C) and 4OHT (Fig. 4D) use the same amino acids Glu353 and Arg394 to locate 
the ligand in the LBD though a strategically positioned 3 phenolic hydroxyl. However, the bulky antiestrogenic side chain (alkylaminoethoxyphenyl) does not permit the closure of Helix 12 to seal the LBD. This is the "stick in the jaws of the crocodile" (Jordan, 1984,Jordan, 1987). However, the role now played by Asp351, and its ability to interact with the alkylaminoethoxy side chain of the SERM governs the intrinsic estrogenic activity of the SERM:ER complex.

The piperidine ring of raloxifene is close to Asp351 thereby shielding and neutralizing Asp351 from further interaction (Fig. 4C). By contrast, the dimethylaminoethoxy side chain of 4OHT is not located as close to Asp351 which remains exposed for further interaction with Helix 12 (Fig. 4D). A simulation with Helix 12 closed with 4OHT demonstrates that Asp351 can now interact with Asp538 via a water bridge. Tyr537 also assists in closing Helix 12 transiently (Jordan et al., 2015). These data now provide a mechanistic explanation of why the 4OHT:ER complex has full estrogen-like actions at the TGF $\alpha$ target gene assay (Levenson and Jordan, 1998,Liu et al., 2001,Liu et al., 2002,MacGregor Schafer et al., 2000,MacGregor Schafer et al., 2001) but raloxifene is a complete antiestrogen. The clinical pharmacology of tamoxifen and raloxifene has been studied in detail with the chemoprevention clinical Study of Tamoxifen and Raloxifene (STAR) trial (Vogel et al., 2006,Vogel et al., 2010). Tamoxifen is uniformly more estrogen-like as a SERM, than raloxifene in several estrogen target endpoints, ie: endometrial hyperplasia, endometrial cancer, hysterectomy based on endometrial changes, and thromboembolic events.

The pivotal role of Asp351 for the modulation of the estrogenic efficacy of the SERM:ER complex has been established using the engineered cell TGF $\alpha$ target model in vitro. In this model a range of specific Asp351 mutant ERs can be stably transfected to study different SERM side chains, so as to derive rules to predict the efficacy of the mutant complex (Liu et al., 2001). 
Simply stated: a non-polar amino acid at 351 predicts no estrogenic activity for the $4 \mathrm{OHT}$ mutant ER complex at the TGF $\alpha$ target. By contrast, replacement of Asp351 with Glu351 or Tyr351 now makes the raloxifene mutant ER complex estrogenic at the TGF $\alpha$ target (Levenson et al., 2001,Liu et al., 2001,Liu et al., 2002). The raloxifene side chain cannot shield and neutralize the charge at amino acid 351 so that Helix 12 can close transiently to activate the signal transduction. The established concepts and rules for SERMs are necessary to consolidate predictable rules whereby the mutant ER found in metastases following exhaustive AI treatment can cause acquired antihormone resistance (Jordan et al., 2015). However, to get to that point of discovery it is important to understand how we believe the treatment strategy of long-term adjuvant antihormonal therapy for breast cancer causes saves lives before selection pressure in micrometastases encourages acquired resistance and recurrence. It is a race against time to prolong life before ER mutations are exposed that subvert the successful treatment strategy (Jordan, 1998,Jordan, 2014a) and kill.

\section{CURRENT TREATMENT FOR BREAST CANCER}

The strategic use of animal models (Jordan, 2015a) to create a road map for the use of long term adjuvant tamoxifen therapy for breast cancer treatment (Jordan, 1978,Jordan et al., 1979,Jordan and Allen, 1980,Jordan, 1983,Jordan, 2014a), heralded a new dimension in the way cancer was treated. Long-term therapy was a maintenance therapy that through the initial clinical trials process using shorter durations of tamoxifen (Cummings et al., 1985,Davies et al., 2013,Delozier et al., 1986,Falkson et al., 1990,Fisher et al., 1986,Fisher et al., 1987,Fisher et al., 1996,NATO, 1983,NATO, 1985,Ribeiro and Palmer, 1983,Ribeiro and Swindell, 1985,SCTO, 1987) ultimately demonstrated increases in survivorship. However, it was the power of the 
Overview Analysis process that occurs every 5 years at Oxford that provides general principles to demonstrate what works and what does not in patient care.

\section{"Longer is better" adjuvant antihormone therapy}

The Early Breast Cancer Trialists' Collaborative Group (EBCTCG) (EBCTCG, 1998) collected and analyzed data from more than 55 trials worldwide from 37,000 women. The results of the analysis demonstrated that adjuvant tamoxifen after 1,2 and 5 years reduced recurrence by 21, 29 and $47 \%$ respectively, reduced the incidence of contralateral breast cancer by 13,26 and $47 \%$ respectively, and reduced mortality by 12,17 and $26 \%$ respectively after a 10 year follow up. However, the incidence of endometrial cancer doubled after 1 or 2 years of adjuvant tamoxifen and quadrupled after 5 years. A later meta-analysis report from EBCTCG (EBCTCG, 2005) on 5 years of adjuvant tamoxifen with 10 and 15 years follow up, demonstrated a significant reduction in mortality in ER-positive breast cancer, regardless of chemotherapy use and age. Furthermore, 5 years of therapy is substantially more effective than 1 or 2 years of adjuvant tamoxifen. A 5 year use of tamoxifen also significantly reduced mortality rates at 15 years follow up. Similar results were observed in an updated meta-analysis from EBCTCG (EBCTCG, 2011). It became obvious that longer adjuvant tamoxifen therapy is an appropriate clinical strategy, thereby validating the data from laboratory models from the 1970's (Jordan, 1978,Jordan et al., 1979,Jordan and Allen, 1980,Jordan, 2014a) that predicted that long-term adjuvant antihormone therapy with tamoxifen was the appropriate clinical strategy. A worldwide Adjuvant Tamoxifen: Longer Against Shorter (ATLAS) (Davies et al., 2013) trial has taken the use of tamoxifen from 5 years to 10 years of continuous adjuvant therapy. The results have shown that patients with ER-positive breast cancer have a significantly higher benefit after 10 years of adjuvant tamoxifen than after 5 years with regards to mortality and recurrence; however, 
the authors noted elevation in adverse effects of treatment with tamoxifen for 10 years, such as pulmonary embolus, ischemic heart disease, and endometrial cancer. Most importantly the report showed that 10 years of tamoxifen may cut by half the mortality rates during the second decade post-diagnosis based on a historical comparison of no treatment controls.

All the reports and trials with adjuvant tamoxifen show, over the course of 30 years, that adjuvant therapy of ER-positive breast cancer with tamoxifen is better the longer it is. Based on the results of the ATLAS trial, ASCO has modified its guidelines and recommended an increase in the duration of treatment with tamoxifen from 5 years to 10 in pre and perimenopausal women (Burstein et al., 2014). However, there is a paradox; the benefit of adjuvant tamoxifen to reduce mortality occurs when the drug is no longer being taken. Tamoxifen is a competitive inhibitor of estrogen action, so when the drug is stopped, estrogen would be expected to increase tumor growth and recurrences; but it does not! This clinical fact demands an explanation and confirmation with other approaches to antihormone therapy.

An alternative to adjuvant tamoxifen treatment of postmenopausal breast cancer patients is long-term treatment with AIs. Aromatase inhibitors target a cytochrome P450 type enzyme called aromatase (CYP19A1) that converts androgen to estrogen, thus blocking the biosynthesis of estrogen that fuels the proliferation of ER-positive breast cancer. Newer AIs made it possible to achieve a safer therapeutic benefit for postmenopausal breast cancer patients (Santen et al., 2009) and as new molecules became more specific and less toxic it has become possible to initiate larger and longer clinical studies to compare the therapeutic effects with tamoxifen, in the adjuvant setting (Baum, 1999).

By early 2000s tamoxifen was the "gold standard" for the treatment of ER-positive breast cancer in both pre- and postmenopausal patients. However it was recognized that tamoxifen 
possesses some potentially life-threatening side effects, such as endometrial cancer and an increase in thromboembolic events. Over the past decade multiple clinical trials investigated the therapeutic advantage of AIs over adjuvant tamoxifen in postmenopausal breast cancer patients. Multiple approaches to adjuvant AI therapy were studied. The simple 5 year continuous AI therapy trials (Baum et al., 2002,Coates et al., 2007,Howell et al., 2005, Thurlimann et al., 2005) demonstrated that the AIs have a better therapeutic effect on disease-free survival, time to recurrence, incidence of contralateral breast cancer, distant metastases and a better safety profile regarding gynecological and vascular side effects. However, it was noted that the AIs caused an increased incidence in bone fracture, hypercholesterolemia and cardiovascular pathologies. Be that as it may, these side effects were not significantly higher in the AI arm of the ATAC study at the 10 year follow up point when compared to the tamoxifen arm, but the incidence rates for recurrent breast cancer were significantly lower in the AI arm of the study (Cuzick et al., 2010,Forbes et al., 2008). Clinical trials (Boccardo et al., 2005,Coombes et al., 2004,Goss et al., 2003,Goss et al., 2005) studying the administration of an AI after 2-3 or even 5 years of adjuvant tamoxifen, including meta-analysis studies (Dowsett et al., 2010), show a significant beneficial therapeutic effect of AIs compared to tamoxifen monotherapy and also after stopping either antiestrogenic adjuvant therapy completely after 5 years.

Based on the data from all the clinical studies, ASCO recommended in its guidelines that postmenopausal women with ER-positive breast cancer should have AIs incorporated in their treatment plans at some point either as an upfront therapy or as a sequential treatment after tamoxifen (Burstein et al., 2010) and that longer antihormonal adjuvant therapy is better with the AIs in postmenopausal patients.

\section{SELECTIVE ER MODULATION}


Since the discovery, trials and use of tamoxifen for the treatment and prevention of breast cancer in women, industry initiated a constant search for a safer and efficient alternative. The market was becoming huge. Compounds such as droloxifene, trioxifene, toremifene and idoxifene were all tested extensively but were unable to show significant advantages over tamoxifen or a better safety profile (Gradishar and Jordan, 1997). The significant landmarks were the discovery of fulvestrant, aromatase inhibitors and raloxifene (Maximov et al., 2013b,McDaniel et al., 2013). When tamoxifen was shown to induce the growth of endometrial cancer in the laboratory, but block estrogen-stimulated breast tumor growth (Gottardis et al., 1988), it was also known that tamoxifen could protect bone and lower cholesterol (Harper and Walpole, 1967,Jordan et al., 1987). These observations translated to confirmatory results from clinical trials (Fornander et al., 1989,Love et al., 1990,Love et al., 1991,Love et al., 1992). The concept of Selective ER Modulation was born (Jordan, 1988a,Lerner and Jordan, 1990) and stated simply: "Important clues have been garnered about the effects of tamoxifen on bone and lipids so it is possible that derivatives could find targeted applications to retard osteoporosis or atherosclerosis. The ubiquitous application of novel compounds to prevent diseases associated with the progressive changes after menopause may, as a side effect, significantly retard the development of breast cancer." (Lerner and Jordan, 1990) Tamoxifen and raloxifene are the original SERMs but their clinical success gave rise to a new generation of medicines (Maximov et al., 2013b). Members include lasofoxifene (CP-336156, Fablyn), bazedoxifene (TSE-424, WAY-140424) and ospemifene (FC-1271a). Applications for SERMs that are approved by the Food and Drug Administration (FDA) include treatment of breast cancer, prevention of breast cancer in high risk women, and the treatment and prevention of osteoporosis. Select agents are used to ameliorate postmenopausal symptoms (bazedoxifene plus conjugated equine estrogens) 
and dyspareunia (ospemifene). Each application is dependent on long-term treatment strategies. As noted in the previous section, long-term adjuvant treatment of breast cancer with antihormonal medicines (tamoxifen or aromatase inhibitors) has created the greatest impact in lives saved.

\section{Long-term SERM treatment for prevention}

In light of the efficacy of tamoxifen to reduce significantly contralateral breast cancer incidence (Cuzick and Baum, 1985) and increase survival of ER-positive breast cancer patients (Baum et al., 1983), it was logical to investigate the cancer preventive properties of tamoxifen in healthy high risk women. Tamoxifen was the first SERM to be used for breast cancer prevention in high-risk women. The NSABP-P1 trial (Fisher et al., 1998) that was initiated to test the worth of tamoxifen as a breast cancer chemopreventive, showed significant preventive properties of tamoxifen in high-risk women at a median follow up of 43 months after 5 years of therapy with tamoxifen. In an update for this study after a 7 year follow up (Fisher et al., 2005) the authors showed that the reduced incidence of breast cancer in the tamoxifen treated arm of the study carried over long after the end of therapy. Other breast cancer prevention trials with tamoxifen, like the IBIS trial (Cuzick et al., 2007), demonstrated that the preventive actions of long-term tamoxifen therapy in high-risk women continued for even 10 years after 5 years of therapy. The updated results from the Royal Marsden trial in the UK demonstrated a significant preventive effect of 8 year tamoxifen treatment evaluated after a 20 year follow up (Powles et al., 2007). Nevertheless, all trials have also indicated that the postmenopausal women taking tamoxifen have a higher incidence of endometrial cancer, deep-vein thrombosis, and pulmonary embolism as adverse side effects of tamoxifen. 
Another SERM that is FDA approved for lowering the incidence of breast cancer in postmenopausal women, during the treatment of osteoporosis, is raloxifene. This compound was tested as a chemopreventive agent against invasive and non-invasive breast cancer in multiple clinical trials like Multiple Outcomes for Raloxifene Evaluation (MORE), Continuing Outcomes Relevant to Evista (CORE) and the Study of Tamoxifen and Raloxifene (STAR) trials. The treatment of high-risk osteoporotic women with raloxifene reduced the risk of ER-positive breast cancer in postmenopausal by $90 \%$ after 3 years of treatment (Cummings et al., 1999), and incidence by about $72 \%$ after 4 years of treatment in the MORE trail (Cauley et al., 2001) and $66 \%$ in the CORE trial (Martino et al., 2004) after 8 years compared to placebo in postmenopausal women. There was a better safety profile with raloxifene than previously noted with tamoxifen as there was no increase in endometrial cancer. Raloxifene caused few gynecological, vascular and pulmonary side effects. In the STAR trial, tamoxifen and raloxifene have the same impact on reducing breast cancer incidence $(\approx 50 \%)$, but raloxifene has a better safety profile (Vogel et al., 2006). However, the STAR trail demonstrated that after a 7.5 year follow up of a 5 year treatment period with both SERMs, raloxifene retained only about $76 \%$ of chemopreventive efficacy of tamoxifen (Vogel et al., 2010). Overall, it is clear that tamoxifen is a unique medicine that is able to retain a high breast cancer preventive efficacy in high-risk women longer than other SERMs (raloxifene is only able to reduce the incidence of breast cancer during continuous treatment). There is tumor suppression with tamoxifen for 10 years after the termination of treatment.

\section{The evolution of acquired resistance to SERMs}

The success of translational research on long-term tamoxifen therapy in laboratory models of rat mammary carcinoma (Jordan, 1983) led to profound improvements in breast cancer 
mortality once 5 years of adjuvant tamoxifen therapy became the standard of care (EBCTCG, 1998,EBCTCG, 2005). Similarly, long-term SERM therapy is the treatment strategy for chemoprevention (Vogel et al., 2006,Vogel et al., 2010). However, the fact that mortality continued to decline after adjuvant therapy was stopped was puzzling.

The first clues of mechanisms occurred with an examination of acquired resistance to tamoxifen (and subsequently raloxifene (Balaburski et al., 2010)) when MCF-7 tumors with acquired tamoxifen resistance were serially transplanted into tamoxifen treated athymic mice (Gottardis and Jordan, 1988). Resistance initially follows a course similar to the treatment of metastatic breast cancer with tamoxifen. At tumor recurrence, tamoxifen stimulated growth occurs as there is a tamoxifen withdrawal response (Howell et al., 1992). Similarly, tamoxifenstimulated acquired resistance occurs in athymic mice or rats implanted with MCF-7 ER-positive tumors (Gottardis and Jordan, 1988,Gottardis et al., 1989a). It was important to test species specificity as tamoxifen is classified as an estrogen in the mouse (Harper and Walpole, 1967). Estradiol also increases tumor growth following the cessation of tamoxifen treatment. This interesting, and unique duality of signal transduction pathways is linked to Insulin-like Growth Factor Receptor 1 (Fagan et al., 2012,Knowlden et al., 2005) and a recent model in vitro has teased out the molecular mechanism of SERM and $\mathrm{E}_{2}$-stimulated growth in a new cell line MCF7:PF (Fan et al., 2014a,Fan et al., 2014b,Fan et al., 2014c).

The model of tamoxifen-stimulated acquired resistance in vivo was used to establish second-line therapies for patients with metastatic breast cancer after drug resistance to tamoxifen occurs. It was predicted that estrogen deprivation or a pure antiestrogen that destroys the ER would have promise (Gottardis and Jordan, 1988,Gottardis et al., 1989b,Lee et al., 2000). A decade later either an $\mathrm{AI}$ or the pure antiestrogen fulvestrant was demonstrated to be equally 
efficacious in patients with metastatic breast cancer who had responded and then failed tamoxifen treatment (Howell et al., 2002,Osborne et al., 2002). However, this laboratory model in vivo did not explain why patients with micrometastatic breast cancer could be effectively treated with adjuvant tamoxifen for 5 years. If the majority of patients with metastatic breast cancer fail tamoxifen after 2-3 years, but adjuvant therapy is effective for 5 years or more, something different is occurring. Again, clues came from animal models.

The serial retransplantation of $\mathrm{MCF}-7$ breast tumors with acquired resistance to tamoxifen into tamoxifen-treated athymic mice for 5 years, resulted in the evolution of tamoxifen-resistant cell populations that had an unanticipated vulnerability in tamoxifen-resistant breast cancer: estrogen-induced apoptosis. The first studies in vivo studies demonstrated that physiologic $\mathrm{E}_{2}$ can cause the rapid regression of tumors with acquired resistance once tamoxifen is stopped. Small tumors i.e.: $<0.4 \mathrm{~cm}^{2}$ usually have a complete response, but larger tumors, i.e. $>1 \mathrm{~cm}^{2}$ rapidly regress, then regrow in the presence of continuing estrogen administration (Wolf and Jordan, 1993, Yao et al., 2000). Indeed, retransplantation of the estrogen-stimulated tumors shows that the tumor is again responsive to the growth inhibitory actions of tamoxifen (Yao et al., 2000). These data led to the conclusion (Wolf and Jordan, 1993, Yao et al., 2000) that: 1) a woman's own estrogen may produce an antitumor effect on the presensitized micrometastatic disease after 5 years of tamoxifen and 2) physiologic estrogen could be employed as a palliative therapy following exhaustive antihormonal therapy of metastatic breast cancer. There is now evidence that both translational research concepts have veracity.

Overall, the laboratory observations show that three phases of acquired SERM-resistance exist (Fig. 5), which depend on the length of SERMs exposure (Jordan, 2004). Tumors with phase I resistance are stimulated by estrogen and SERMs, but inhibited by AIs and fulvestrant; 
tumors with phase II resistance are stimulated by SERMs, but are inhibited by estrogen due to apoptosis; tumors with phase III resistance grow autonomously regardless of SERMs, but are inhibited by estrogen with apoptosis (Jordan, 2004). The cell populations are clearly being modulated over years of therapy so that emerging resistant cells that adapt to change can grow in a new environment. Understanding this process provides an opportunity to save more lives.

We will first address the potential mechanisms of acquired antihormone resistance before describing the clinical observations in the final section entitled "Clinical consequences of estrogen deprivation".

\section{POTENTIAL MECHANISMS OF ACQUIRED ANTIHORMONE RESISTANCE}

\section{SERM-stimulated growth}

Phase I acquired resistance to SERMs is unique because the growth of resistant tumors is dependent on SERMs (Gottardis and Jordan, 1988,Gottardis et al., 1989a, Yao et al., 2000). All of the previously stated observations in animal models of human disease (Wolf and Jordan, 1993, Yao et al, 2000) suggest that ER is utilized by SERMs or estrogen to stimulate cell growth. However, no mechanism has been established to explain this paradox. Our recently described cell line in vitro provides an indispensable, yet unanticipated new model to decipher SERMstimulated growth directly (Fan et al., 2014b). The finding that c-Src tyrosine kinase is increased in long-term estrogen-deprived MCF-7:5C cells (Fan et al., 2013) and inhibition of c-Src in short-term (7 days) experiments would reversibly block estrogen-induced apoptosis (Fan et al., 2012,Fan et al., 2013), created an opportunity to determine what long-term inhibition of c-Src in the presence of $\mathrm{E}_{2}$ would do to the biological properties of the surviving cell populations (Fan $e t$ $a l ., 2014 \mathrm{c}$ ). A two month period of selection pressure was chosen, as this is the time period used clinically to evaluate tumor response to therapy. The new cell population (MCF-7:PF) that grew 
out under the pressure of estrogen plus the c-Src inhibitor is particularly interesting as, for the first time, it replicates in vitro Phase I acquired resistance to SERMs in vivo (Gottardis and Jordan, 1988,Wardell et al., 2013). The cells grow robustly with $\mathrm{E}_{2}$ (Fan et al., 2014c) but also SERMs will stimulate growth in vitro based on their individual intrinsic estrogenic efficacy as treatments in vitro (Fan et al., 2014b). All evidence suggests that the ER is a major driver of growth utilized by both estrogen and SERMs in resistant models in vivo (Gottardis and Jordan, 1988,Gottardis et al., 1989a, Yao et al., 2000) and in vitro (Fan et al., 2014c,Fan et al., 2014b). In contrast to estrogen that activates classical ER-target genes in the genome, SERMs continue to act as effective antiestrogens to inhibit classified ER-target genes, even during growth stimulation (Fan et al., 2014b,Fan et al., 2014a). This result is consistent with our previous finding in vivo that growth of tumors by tamoxifen or fulvestrant is potentially independent of ER transcriptional activity, as evidenced by lack of induction of estrogen-responsive genes at the genome (Osipo et al., 2007). Other groups have reported similar observations with tamoxifen suppressing classical ERE-regulated genes despite acquired resistance in vitro (Hutcheson et al., 2003) or in vivo (Massarweh et al., 2008).

\section{Estrogen-induced apoptosis}

Low concentration ( $1 \mathrm{pM}$ to $1 \mathrm{nM}$ ) estrogen-induced apoptosis is an unanticipated discovery from the study of long-term antiestrogen treatment in breast cancer (Lewis et al., 2005a,Lewis et al., 2005b,Liu et al., 2003,Osipo et al., 2003,Song et al., 2001,Wolf and Jordan, 1993,Yao et al., 2000). Long-term laboratory studies with either SERMs, e.g. tamoxifen and raloxifene (Liu et al., 2003, Osipo et al., 2003, Yao et al., 2000), or estrogen deprivation (Lewis et al., 2005a,Song et al., 2001), demonstrate that the molecular biology of estrogen action changes dramatically to become an apoptotic trigger with 5 or more years of treatment. Thus, estrogen 
deprivation produces the same selective pressure on MCF-7 cells as SERMs to create selective cellular populations vulnerable to estrogen-induced apoptosis. The new biology of estrogeninduced apoptosis has recently been reviewed (Jordan, 2015b). These laboratory data provide the scientific rationale for the subsequent finding that conjugated equine estrogen (CEE) treatment alone, in the Women Health Initiative (WHI), causes a decrease in the incidence of breast cancer in women in their 60's i.e.: 10 years of estrogen deprivation following menopause (Anderson $e t$ al., 2004,Rossouw et al., 2002). Decreased mortality is sustained for 6 years after CEE is stopped (Anderson et al., 2012). It appears that at least five years of estrogen deprivation from menopause is necessary (Beral et al., 2011) to select for vulnerable breast cancer cells that will be killed by physiologic estrogen replacement therapy (Jordan, 2014b,Obiorah and Jordan, 2013).

We have further noted several unique aspects of estrogen-induced apoptosis. Apoptosis it is delayed (and reversible) compared to the immediate action of cytotoxic chemotherapy (Obiorah et al., 2014b). The conformation of the liganded ER complex modulates decisions for early apoptosis or early antagonism of apoptosis and late apoptosis (Obiorah et al., 2014a,Sengupta et al., 2013) (to be continued in more detail in the section "Ligands to activate the wild-type ER"). $E_{2}$ initiates an unfolded protein response (UPR) in endoplasmic reticulum and an inflammatory response prior to apoptosis (Ariazi et al., 2011,Fan et al., 2013). Induction of endoplasmic reticulum stress by $\mathrm{E}_{2}$ is earlier than oxidative stress (Fan et al., 2013), and $\mathrm{E}_{2}$ induces apoptosis via ER genomic mechanisms (Fan et al., 2013). A variety of apoptosis-related genes are activated by $\mathrm{E}_{2}$ and blocked by 4-OHT in estrogen-deprived cells (Fan et al., 2013,Sweeney et al., 2014a) (Fig. 6). Currently, we are investigating early ER-mediated events 
that can be modulated to discover the actual triggering of estrogen-induced apoptosis in the correctly configured and selected cell population.

\section{ER and growth factor receptors crosstalk}

A significant alteration of ER function observed in SERM-resistant cells is the activation of multiple membrane-associated molecules including focal adhesion molecules, adapter proteins, and growth factor receptors (Fig. 7). Accumulating evidence suggests that growth factor receptors, such as insulin-like growth factor-1 receptor (IGF-1R), HER-2, and epidermal growth factor receptor (EGFR) are implicated in acquired SERM resistance (Fagan et al., 2012,Fan et al., 2007,Fan et al., 2014b,Knowlden et al., 2005, Shou et al., 2004), but their precise contributions are not well understood. The laboratory model with MCF-7 cells is consistent with the clinic observation that aromatase inhibitor or fulvestrant are equally effective after the failure of tamoxifen treatment (Howell et al., 2002,Osborne et al., 2002). It therefore appears that ER remains fully functional after acquired tamoxifen resistance occurs and tamoxifen is stopped. In our phase I SERM-resistant cell model, we provide evidence that 4-hydroxytamoxifen (4-OHT) stimulates growth of MCF-7:PF cell in an ER-dependent manner despite suppression of classical ER-target genes. Further examination reveals that 4-OHT functions as an agonist to enhance the non-genomic activity of ER and activates focal adhesion molecules to increase phosphorylation of IGF-1R (Fan et al., 2014b). All of these events promote 4-OHT-stimulated cell growth. Other groups have reported that the non-genomic activity of ER is enhanced by tamoxifen which facilitates the interaction of the ER with growth factor receptors, HER2 or EGFR (Fan et al., 2007,Shou et al., 2004). Our recent observations demonstrate that the non-genomic activity of ER is diversely modulated via multiple membrane-associated molecules including IGF-1R to subvert long-term nuclear suppression by tamoxifen (Fan et al., 2014b). The targeting of these 
membrane-associated pathways and investigating new, unanticipated combination therapies may have further clinical potential to decipher and treat endocrine-resistant patients.

Altogether, acquired resistance to SERMs is not one dimensional. There is no simple solution. Resistant cell populations are in a constant evolution, depending upon selection pressure and the availability of growth stimuli that enhances population plasticity and the survival of new populations. These functional alterations lead to acquired SERM resistance.

We will now focus down on the ER as the principal signal transduction pathway that governs the replication and death of breast cancer cells. However, the biology of the ER is dependent upon the evolution of cell populations. Cell populations that are estrogen-dependent for growth remain so during short-term estrogen deprivation. Long-term estrogen deprivation causes population changes with estrogen-induced apoptosis. The ER remains constant but the cell populations have different decision networks (Jordan, 2014c). New laboratory and clinical observations have recently enhanced our evolving "molecular model" of acquired antihormone resistance. These new concepts will be presented and integrated.

\section{Ligands to activate the wild-type ER}

The stimulatory activity of the ER is governed by its estrogenic ligands thereby fueling breast cancer cell growth and also affecting other tissues around the woman's body. The shape of the ligand causes activation of the ER by different conformation-dependent mechanisms. This has been dealt with in detail in the sections "Estrogen Receptor" and "Molecular Model of Estrogen/Antiestrogen Action". Here, we will focus on the classification of ligands that activate the ER and trigger long-term estrogen-deprived cell population to be killed.

Estrogens are a varied group of ligands that bind to the ER to cause growth or can trigger apoptosis in long-term estrogen-deprived ER-positive breast cancer cells. Natural estrogens, e.g.: 
estrone $\left(E_{1}\right), E_{2}$, estriol $\left(E_{3}\right)$, equilin and equilenin are planar steroidal ligands, whereas synthetic estrogens can be either planar e.g.: bisphenol A, diethylstilbestrol (DES); or angular triphenylethylene estrogens (TPEs). All estrogens can initiate vaginal cornification in ovariectomized mice (Allen and Doisy, 1923). However, estrogens can be classified into planar Class I estrogens or angular Class II estrogens based upon the ability to initiate expression of reporter gene in engineered cell systems with expressed either wild-type or Asp351Gly mutant ER (Jiang and Jordan, 1992,MacGregor Schafer et al., 2000). The assays (Jordan et al., 2001) provide a clear yes/no answer by activating model reporter genes, such as TGF $\alpha$ or luciferase with an ERE promoter. All estrogens activate TGF $\alpha$ with wild-type ER, but only planar Class I estrogens activate reporter mRNA expression with the mutant Asp351Gly ER. The conformation of the ER complex with a planar estrogen closes Helix 12 appropriately, whereas the angular TPE estrogens have no activity with the Asp351Gly ER. A mutated Asp351Gly cannot interact with Helix 12 with the steric hindrance produced by a TPE in the LBD. Therefore, there is no coactivator binding or transactiviation of the reporter gene (Maximov et al., 2010,Obiorah et al., 2014a,Sengupta et al., 2013). With this classification in mind it is now reasonable to consider ligands that stimulate breast cancer cell growth or ligands that alter the apoptotic response in long-term estrogen-deprived ER-positive breast cancer cell lines.

All class I and II estrogens increase the replication of breast cancer cell lines, but another natural estrogen 27-hydroxycholesterol $(27 \mathrm{HC})$, synthesized in the body, can activate the. Like $\mathrm{E}_{2}, 27 \mathrm{HC}$ is a derivative of cyclopentanoperhydrophenanthrene and has a similar structure. It has been reported that $27 \mathrm{HC}$ can activate the ER, and is considered the first naturally occurring SERM (DuSell et al., 2008) by, most-likely, inducing a unique conformation of the ER. Like $\mathrm{E}_{2}$ 27HC induces degradation of the ER in cells and also induces breast cancer cell proliferation 
(DuSell et al., 2008). However, SERMs were defined as modulating the ER selectively, as the intent was to create an ideal medicine to prevent multiple diseases in women (Jordan, 2003b,Jordan, 2003c). Thus, a synthetic SERM would be required to prevent breast cancer, prevent osteoporosis, prevent an increase in endometrial cancer and prevent atherosclerosis (Jordan, 2001,Lerner and Jordan, 1990). In contrast, 27HC seems to be deleterious at all sites thus far investigated. $27 \mathrm{HC}$ the metabolite increases breast cancer cell replication in vitro (DuSell et al., 2008) and in vivo (Nelson et al., 2013,Wu et al., 2013), prevents the beneficial effects of estrogen on improving bone density (DuSell et al., 2010) and inhibits the beneficial cardiovascular effects of estrogen (Umetani et al., 2007).

High-dose synthetic estrogens were the standard in the treatment of advanced breast cancer in women (Haddow et al., 1944,Kennedy and Nathanson, 1953) until tamoxifen replaced estrogen therapy (Jordan, 2003c). The synthetic estrogens that were initially used in the clinic are both the planar DES and the angular triphenylethylenes (TPEs). Recent studies (Maximov et al., 2014, Obiorah et al., 2014a) addressed whether estrogen-induced apoptosis is dependent on the conformation of the ER in antiestrogen-resistant cells. Studies demonstrated a clear dependency of estrogen-induced apoptosis on the type of the estrogen and thus the ER conformation. All of the planar Class I estrogens, like $\mathrm{E}_{2}$, DES, equilin and equilinin, are able to induce apoptosis within a week in the estrogen-deprived breast cancer cell model, but the TPE, Class II estrogens initially blocked estrogen-induced apoptosis (Sengupta et al., 2013). However, the issue is time. The Class II TPEs have a delayed apoptosis (Maximov et al., 2014,Obiorah et al., 2014a).

\section{Mutations of the ER}

During the past couple of years numerous studies have been published describing the identification and distribution of mutations of the ER in primary breast cancer and it metastases 
following the failure of antihormonal therapy (Jeselsohn et al., 2014,Li et al., 2013,MerenbakhLamin et al., 2013,Robinson et al., 2013,Toy et al., 2013,Yu et al., 2014). These mutations are summarized in Table 1. The evolution of our understanding of the mechanics of the ER complex liganded with an estrogen or an antiestrogen was described earlier in this review (A Molecular Model of Estrogen/Antiestrogen Action). This serves as the basis for understanding a unifying mechanism of action for SERM and aromatase inhibitor resistance. A unifying molecular model of SERM action and AI resistance has been reported recently (Jordan et al., 2015), but the conclusions for the mechanism of AI resistance based on the majority of mutations at aa537 and 538 will be summarized here. The planar (class I) estrogen $\mathrm{E}_{2}$ is located through its 3 phenolic hydroxyl by aminoacids Glu353 and Arg394 in the LBD (Fig. 4A). The 16 alcoholic hydroxyl is tethered by His524 (Fig. 4A). This creates a scaffold to fold the LBD around the steroid and seal the cavity with closure by Helix 12. The amino acids Tyr537 and Asp538 facilitate sealing of the LBD. The role of Asp351 in the activation of the ER complex is confirmed by the structures of 4OHT and raloxifene in the LBD (Fig. 4C and 4D). The antiestrogenic side chain of raloxifene shields and neutralizes Asp351 via the piperidine ring preventing closure of Helix 12. The modelling of the ER mutations in 537 and 538, following AI resistance, show that Helix 12 closure of an unoccupied LBD occurs by interaction of Ser537 and Gly538 with Asp351; thus, Asp351 is the essential anchor aminoacid (Jordan et al., 2015,Toy et al., 2013). Thus, the consistent identification of mutations in the ER is confirmed as an important mechanism of antihormone resistance through modulation of the tumor ER. However, how we use this information to design new SERMs that cause destruction of the ER in breast cancer during adjuvant therapy may be an important way forward for therapeutics. This will be addressed in the 
final sections Perspective and Vision following the translation of estrogen-induced apoptosis to clinical practice.

\section{CLINICAL CONSEQUENCES OF ESTROGEN DEPRIVATION}

\section{Palliative treatment of metastatic breast cancer following prior antihormonal therapy}

The scientific "rediscovery" of estrogen therapy (Wolf and Jordan, 1993, Yao et al., 2000) reawaked clinical interest in the reuse of palliative estrogen therapy. Lonning and coworkers (Lonning et al., 2001) studied a small number of patients who had received exhaustive antihormonal therapy, but were now treated with high dose DES therapy (15 mg/day). Response rates were encouraging for $38 \%$ of patients after 6 months of therapy, but one patient had a complete response on high dose estrogen and after 5 years of continuous therapy, treatment was stopped. The patient remained disease-free for the next six years (Lonning, 2009). It is important to emphasize that the principal barrier to high dose estrogen therapy over extended periods is serious, life threatening side effects such as thromboembolic disorders. However, the laboratory studies emphasize the value of low dose estrogen therapy following prolonged antihormonal therapy and acquired resistance (Wolf and Jordan, 1993, Yao et al., 2000). Ellis (Ellis et al., 2009) addressed the principle in the clinic by comparing high (30 mg/day) and low dose (6 $\mathrm{mg} /$ day) $\mathrm{E}_{2}$ treatment following the failure of adjuvant $\mathrm{AI}$ therapy. The conclusion was that the clinical benefit was the same for both high and low doses, but side effects were far less with low dose treatment.

\footnotetext{
"Carry over" beneficial effects following long-term adjuvant tamoxifen therapy or an application as a chemopreventive in high-risk women.
} 
Based on the laboratory (Wolf and Jordan, 1993, Yao et al., 2000) and clinical data published (EBCTCG, 2005,Fisher et al., 2005) more than a decade ago, it was clear that the application of tamoxifen to treat micrometastatic disease is very different, biologically, than the treatment of metastatic breast cancer (stage IV). However, the fact that tamoxifen works better as an antitumor agent in micrometastatic disease than in metastatic breast cancer complies with the therapeutic principle that low tumor burden responds better to treatment than high tumor burden. With a small tumor burden there is less mutational heterogeneity and less well established tumor vasculature and protection from hostile insults, i.e., therapy. The observation, however, did not explain why stopping long-term adjuvant therapy or chemoprevention with a "tumoristatic antiestrogen" did not again return tumors to growth once estrogen could bind to the ER.

Recently, an evaluation of all current data (Jordan, 2014b) has concluded that the selection pressure exerted by long-term tamoxifen treatment creates vulnerable new cell populations that are killed by the woman's own estrogen, once tamoxifen is cleared. It is longterm estrogen deprivation that is the key to selection to a state of vulnerability to low dose estrogen therapy (Jordan, 2014a,Jordan, 2014b). Indeed, this idea, with its genesis 15 years ago (Wolf and Jordan, 1993,Yao et al., 2000) set the stage for what is the Study of Letrozole Extension (SOLE) trial.

\section{Drug holidays after long-term antihormone therapy}

AIs have become the standard of care for postmenopausal women with ER-positive breast cancer. A novel treatment regimen with adjuvant AI letrozole is currently being evaluated as the Study of Letrozole Extension (SOLE) trial. The trial is designed to test the concept of intermittent treatment of postmenopausal breast cancer patients who had 4-6 years of prior antihormonal therapy after surgery. The trial compares two groups of randomized patients: 
taking continuous letrozole for 5 years, or in patients that have 3 month "drug holiday" for the first 4 years of treatment followed with a full year 5 of treatment with letrozole. The idea behind this concept is that the long-term antihormone therapy with an AI will sensitize nascent breast cancer cells to woman's own estrogen as a tumoricidal agent (Yao et al., 2000). The veracity of this concept is supported by an array of laboratory studies that has been recently reviewed (Jordan, 2014b). Even after the results of the ATLAS trial on 10 years of adjuvant tamoxifen were included in ASCO's guidelines (Burstein et al., 2014), it is still recommended that postmenopausal patients should receive 5 years of adjuvant therapy with an AI or AI followed after tamoxifen, or if the patient has received 5 years of tamoxifen already, then she should be offered to either continue on tamoxifen or switch to an AI for a total 10 years of extended endocrine therapy. The results of the SOLE trial with drug holidays for the AI may have important ramifications for clinical care. Options are discussed in the last section Perspectives and Visions.

Phytoestrogens use in the community to reduce breast cancer risk or as a natural estrogen replacement therapy (ERT)

The phytoestrogens are classified as Class I estrogens based on the fact that they can occupy the LBD of the ER and allow the closure of Helix 12 (Bentrem et al., 2003, Obiorah et al., 2014c). However, the phytoestrogens as a group have a low binding affinity for the ER and are therefore less potent than the female sex hormones $\mathrm{E}_{1}, \mathrm{E}_{2}$ and $\mathrm{E}_{3}$.

However, unlike the carcinogenic potential of steroidal estrogens the epidemiology literature (Chen et al., 2014,Nagata et al., 2014,Wu et al., 2008) supports the view that soy diet can reduce the risk of breast cancer. However, in western society this has been translated into the use of soy in adulthood to prevent breast cancer. Definitive evidence for the hypothesis in the 
clinical literature has not been forthcoming. Another use of phytoestrogens is as a safe ERT in the community, but a recent study by Shike and coworkers (Shike et al., 2014) demonstrate that phytoestrogens may not be safe.

If soy is taken around the time of surgery in patients with predominantly ER-positive breast cancer, there is an increase in breast cancer gene activity associated with cell replication. Most of the patients in the study were around menopause (Shike et al., 2014) which is consistent with the rules that patients must be beyond 5 years from menopause to benefit from estrogen administration (Haddow, 1970,Jordan, 2014a). In other words, patients must have a 5 year period of estrogen deprivation to allow selection pressure to create a surviving, yet vulnerable population of cells that are able to be sacrificed during estrogen (any estrogen) therapy. The study described by Shike et al (Jordan, 2014c,Shike et al., 2014) did not define this requirement. A future study with phytoestrogens used five years after menopause to examine breast cancer cell replication will validate the safety profile of these natural estrogens to be used as a ERT.

\section{Hormone Replacement Therapy}

After the end of World War II, the idea developed that natural estrogen, i.e.: conjugated equine estrogens (CEE), could be used successfully to replace lost estrogen post-menopause. This idea took hold with the gynecology community to reduce menopausal symptoms and was subsequently expanded to include ERT to build and increase postmenopausal bone density and reduce fractures. In so doing, treatment practice advanced from a few months or years to become decades. Regrettably, the long-term use of unopposed CEE after menopause resulted in an increased risk of endometrial cancer (Beral et al., 2005,Shapiro et al., 1985,Smith et al., 1975,Ziel and Finkle, 1975). As a result, the synthetic progestin medroxyprogesterone acetate (MPA) was selected to protect the uterus from the proliferative effects of CEE. During the 
1990's the proposition was advanced that a combination of CEE and MPA, could prevent coronary heart disease (CHD) in postmenopausal women and much epidemiologic data was collected to support this application. To address the question, the Woman's Health Initiative (WHI) was conceived by the $\mathrm{NIH}$, and two separate placebo-controlled trials were created. In the trial of MPA/CEE (HRT) postmenopausal women, in the main in their sixth decade with an intact uterus, were randomized to HRT or placebo and treated until required to stop by prearranged stop rules. In the trial of CEE alone (ERT) postmenopausal women in their sixth decade with hysterectomy, were randomized to ERT or placebo until required to stop. This age group was selected because the end point for the trial was to show a benefit in protecting women from CHD and age after menopause is important because risk for CHD increases. However, this did not prove to be the case. The HRT trial was stopped because of the predicted increase in breast cancer that crossed the stop rules but the ERT trial did not. This trial was stopped two years later when the population taking ERT crossed the stroke threshold stop rule. Surprisingly, at evaluation the ERT group had a decrease in breast cancer (Anderson et al., 2004) that was consolidated by subsequent analysis (Anderson et al., 2012,Chlebowski et al., 2015). These conflicting data created considerable confusion within the clinical community and patients. Fortunately, knowledge of the new biology of estrogen-induced apoptosis in estrogen-deprived breast cancer cell population was able to rescue the intellectual void (Jordan and Ford, 2011). Nevertheless, the question was raised: "so if CEE causes apoptosis of vulnerable nascent estrogen-deprived cell populations in the postmenopausal breast, why does MPA plus CEE cause an increase in breast cancer?"

An earlier pathway analysis of estrogen-induced apoptosis (Ariazi et al., 2011) identified an initial inflammatory response associated with the earliest stages of the apoptotic mechanism 
(Fig. 8). We suggested that glucocorticosteroids could block estrogen-induced apoptosis (Ariazi et al., 2011) and this proved to be the case: dexamethasone blocked estrogen-induced apoptosis (Obiorah et al., 2014c). However, MPA is not a pure synthetic progestin, but exhibits associated glucocorticosteroid activity (Koubovec et al., 2005). Indeed, the synthetic antiprogestin RU486 is not a pure progestin antagonist but has significant antiglucocorticoid activity (Chobert et al., 1983). Similarly, 19-nortestosterone derived progestins in oral contraceptives are also estrogenic (Catherino et al., 1993,Jeng et al., 1992). Thus the progestational steroids have promiscuity regarding interaction with progesterone, glucocorticosteroid or estrogen receptors. Commensurate with these observations, a recent study demonstrates that two factors could be involved in the creation of the tumorigenic action in the HRT trial of the WHI: the intrinsic glucocorticoid activity of MPA and the dimension of a long time necessary for cancer cell selection and population regrowth. The facts that MPA blocks estrogen-induced apoptosis because of weak glucocorticoid activity and that the long-term selection pressure permits the surviving cells to grow into tumors with new characteristics (Sweeney et al., 2014b), now creates, for the first time, a mechanistic explanation for the results of the two trials of the WHI (Anderson et al., 2012). For the future, a progestin without glucocorticosteroid properties but with estrogenic properties could enhance estrogen-induced apoptosis of nascent breast cancer in postmenopausal women, $>5$ years post menopause, whilst simultaneously protecting the uterus through differentiation (Sweeney et al., 2014b).

\section{PERSPECTIVE AND VISION}

The first chemical therapy to treat any cancer rationally, following the translational research paradigm through to clinical trial, was the application of high dose estrogen to treat metastatic breast cancer in postmenopausal women (Haddow et al., 1944). The principles 
developed by Haddow to select patients for successful high dose estrogen therapy (Haddow, 1970) have stood the test of time and through laboratory studies become rules today. Estrogen treatment to cause tumor regression requires five years of estrogen deprivation to create vulnerable populations of tumor cells (Jordan, 2014a,Jordan, 2014b,McDaniel et al., 2013). The evidence from the ERT trial of the WHI supports the concept of estrogen killing in long-term estrogen deprived nascent breast cancer cells (Anderson et al., 2004,Anderson et al., 2012). This dovetails nicely to explain the observation with long-term tamoxifen therapy and AIs causing long-term decreases in tumor recurrences, following the cessation of therapy, by a woman's endogenous estrogen killing metastases (Jordan, 2014b). So, if these are the factors that promote the vulnerability of breast cancer, what factors prevent estrogen-induced apoptosis? It would seem that glucocorticosteroids are a culprit and this factor is proposed to be the cause of the increase in breast cancer incidence noted in the CEE/MPA HRT studies (Sweeney et al., 2014b). That being said, perhaps, it is possible to transiently decrease tumor burden prospectively in the adjuvant or prevention setting with a novel selective glucocorticosteroid receptor modulator plus CEE. This approach has been proposed to enhance the effectiveness of chemotherapy to induce apoptosis in triple-negative breast cancer (Skor et al., 2013). The inhibitory effects of glucocorticosteroids on estrogen-induced apoptosis may be a barrier to earlier responses after long-term adjuvant antihormonal therapy. If SOLE shows some benefit with AI holidays, could CEE be used in the adjuvant setting for long-term AI treatment, but with a one week estrogen purge each year?

A decade ago there were only a handful of papers from laboratory research focused on estrogen-induced antitumor actions (Lewis et al., 2005a,Lewis et al., 2005b,Liu et al., 2003, Osipo et al., 2003,Song et al., 2001,Wolf and Jordan, 1993, Yao et al., 2000) and one 
clinical study (Lonning et al., 2001). Today the expanded understanding of mechanisms and modulation of estrogen-induced apoptosis has recreated a new biology of estrogen action awaiting new approaches as the horizons widen (Jordan, 2015a). In closing, it could be questioned why this natural process of killing breast cancer cells occurs at all? Perhaps, the cancer science will now lead to an understanding of the regulation of natural processes in bone physiology with estrogen triggering osteoclast destruction during ERT. The physiologic process of bone remodeling during estrogen deprivation is inherent but repressed in the human genome of breast cancer. The estrogen deprived breast cancer cells may be "recalling" the repressed gene set to survive the estrogen-deprivation in cancer. The vulnerability of estrogen-deprived breast cancer may be the bone cell specific process of osteoclast regulation at menopause or during estrogen treatment.

The past decade has taught us much about how physiologic estrogen can trigger apoptosis in prepared estrogen-deprived populations of breast cancer cells. Following early results in the pre-apoptotic action of the $\mathrm{E}_{2}$ :ER complex has been most instructive. However, the goal for future progress is the discovery of a "triggering event". If following the molecular path of the $\mathrm{E}_{2}$ :ER complex in estrogen-deprived ER positive breast cancer leads to a "triggering event" then this would potentially become a new druggable target to cause the cellular collapse of the hormone-independent (ER-negative) cancer cell. This vision of a new target may lead to opportunities for the treatment of all cancers not previously considered.

\section{ACKNOWLEDGEMENTS}

Only the authors prepared this manuscript and the funding organizations played no role. This work (VCJ, PF, PYM) was supported by the Department of Defense Breast Program under Award number W81XWH-06-1-0590 Center of Excellence; the Susan G Komen for the Cure 
Foundation under Award number SAC100009; and the National Institutes of Health MD Anderson's Cancer Center Support Grant, CA016672. The views and opinions of the author(s) do not reflect those of the US Army or the Department of Defense. RC gratefully acknowledges the Institute of Chemistry Timisoara of the Romanian Academy, Project no. 1.1/2015 for financial support. 


\section{References}

Allen, E. and Doisy, E.A., 1923. An ovarian hormone, J Am Med Assoc. 81, 819-821.

Anderson, G.L., Limacher, M., Assaf, A.R., Bassford, T., Beresford, S.A., Black, H., Bonds, D., Brunner, R., Brzyski, R., Caan, B. et al., 2004. Effects of conjugated equine estrogen in postmenopausal women with hysterectomy: the Women's Health Initiative randomized controlled trial, JAMA. 291, 1701-12.

Anderson, G.L., Chlebowski, R.T., Aragaki, A.K., Kuller, L.H., Manson, J.E., Gass, M., Bluhm, E., Connelly, S., Hubbell, F.A., Lane, D. et al., 2012. Conjugated equine oestrogen and breast cancer incidence and mortality in postmenopausal women with hysterectomy: extended follow-up of the Women's Health Initiative randomised placebo-controlled trial, Lancet Oncol. 13, 476-86.

Ariazi, E.A., Cunliffe, H.E., Lewis-Wambi, J.S., Slifker, M.J., Willis, A.L., Ramos, P., Tapia, C., Kim, H.R., Yerrum, S., Sharma, C.G. et al., 2011. Estrogen induces apoptosis in estrogen deprivation-resistant breast cancer through stress responses as identified by global gene expression across time, Proc Natl Acad Sci U S A. 108, 18879-86.

Balaburski, G.M., Dardes, R.C., Johnson, M., Haddad, B., Zhu, F., Ross, E.A., Sengupta, S., Klein-Szanto, A., Liu, H., Lee, E.S. et al., 2010. Raloxifene-stimulated experimental breast cancer with the paradoxical actions of estrogen to promote or prevent tumor growth: a unifying concept in anti-hormone resistance, Int J Oncol. 37, 387-98.

Baum, M., Brinkley, D.M., Dossett, J.A., McPherson, K., Patterson, J.S., Rubens, R.D., Smiddy, F.G., Stoll, B.A., Wilson, A., Lea, J.C. et al., 1983. Improved survival among patients treated with adjuvant tamoxifen after mastectomy for early breast cancer, Lancet. 2, 450.

Baum, M., 1999. Use of aromatase inhibitors in the adjuvant treatment of breast cancer, Endocr Relat Cancer. 6, 231-4.

Baum, M., Budzar, A.U., Cuzick, J., Forbes, J., Houghton, J.H., Klijn, J.G., Sahmoud, T. and Group, A.T., 2002. Anastrozole alone or in combination with tamoxifen versus tamoxifen alone for adjuvant treatment of postmenopausal women with early breast cancer: first results of the ATAC randomised trial, Lancet. 359, 2131-9.

Beatson, G.T., 1896. On the treatment of inoperable cases of carcinoma of the mamma: suggestions for a new method of treatment, with illustrative cases., Lancet. 2, 104-107.

Bentrem, D., Fox, J.E., Pearce, S.T., Liu, H., Pappas, S., Kupfer, D., Zapf, J.W. and Jordan, V.C., 2003. Distinct molecular conformations of the estrogen receptor alpha complex exploited by environmental estrogens, Cancer Res. 63, 7490-6.

Beral, V., Bull, D., Reeves, G. and Million Women Study, C., 2005. Endometrial cancer and hormone-replacement therapy in the Million Women Study, Lancet. 365, 1543-51.

Beral, V., Reeves, G., Bull, D., Green, J. and Million Women Study, C., 2011. Breast cancer risk in relation to the interval between menopause and starting hormone therapy, J Natl Cancer Inst. 103, 296-305.

Berthois, Y., Katzenellenbogen, J.A. and Katzenellenbogen, B.S., 1986. Phenol red in tissue culture media is a weak estrogen: implications concerning the study of estrogenresponsive cells in culture, Proc Natl Acad Sci U S A. 83, 2496-500.

Boccardo, F., Rubagotti, A., Puntoni, M., Guglielmini, P., Amoroso, D., Fini, A., Paladini, G., Mesiti, M., Romeo, D., Rinaldini, M. et al., 2005. Switching to anastrozole versus 
continued tamoxifen treatment of early breast cancer: preliminary results of the Italian Tamoxifen Anastrozole Trial, J Clin Oncol. 23, 5138-47.

Boyd, S., 1900. On oopherectomy in the cancer of the breast., Br Med J. ii, 1161-1167.

Brzozowski, A.M., Pike, A.C., Dauter, Z., Hubbard, R.E., Bonn, T., Engstrom, O., Ohman, L., Greene, G.L., Gustafsson, J.A. and Carlquist, M., 1997. Molecular basis of agonism and antagonism in the oestrogen receptor, Nature. 389, 753-8.

Burstein, H.J., Prestrud, A.A., Seidenfeld, J., Anderson, H., Buchholz, T.A., Davidson, N.E., Gelmon, K.E., Giordano, S.H., Hudis, C.A., Malin, J. et al., 2010. American Society of Clinical Oncology clinical practice guideline: update on adjuvant endocrine therapy for women with hormone receptor-positive breast cancer, J Clin Oncol. 28, 3784-96.

Burstein, H.J., Temin, S., Anderson, H., Buchholz, T.A., Davidson, N.E., Gelmon, K.E., Giordano, S.H., Hudis, C.A., Rowden, D., Solky, A.J. et al., 2014. Adjuvant endocrine therapy for women with hormone receptor-positive breast cancer: american society of clinical oncology clinical practice guideline focused update, J Clin Oncol. 32, 2255-69.

CancerResearchUK.org. Worldwide cancer incidence statistics.

Catherino, W.H., Jeng, M.H. and Jordan, V.C., 1993. Norgestrel and gestodene stimulate breast cancer cell growth through an oestrogen receptor mediated mechanism, Br J Cancer. 67, 945-52.

Catherino, W.H., Wolf, D.M. and Jordan, V.C., 1995. A naturally occurring estrogen receptor mutation results in increased estrogenicity of a tamoxifen analog, Mol Endocrinol. 9, 1053-63.

Cauley, J.A., Norton, L., Lippman, M.E., Eckert, S., Krueger, K.A., Purdie, D.W., Farrerons, J., Karasik, A., Mellstrom, D., Ng, K.W. et al., 2001. Continued breast cancer risk reduction in postmenopausal women treated with raloxifene: 4-year results from the MORE trial. Multiple outcomes of raloxifene evaluation, Breast Cancer Res Treat. 65, 125-34.

Chang, C.Y., Norris, J.D., Gron, H., Paige, L.A., Hamilton, P.T., Kenan, D.J., Fowlkes, D. and McDonnell, D.P., 1999. Dissection of the LXXLL nuclear receptor-coactivator interaction motif using combinatorial peptide libraries: discovery of peptide antagonists of estrogen receptors alpha and beta, Mol Cell Biol. 19, 8226-39.

Chen, M., Rao, Y., Zheng, Y., Wei, S., Li, Y., Guo, T. and Yin, P., 2014. Association between soy isoflavone intake and breast cancer risk for pre- and post-menopausal women: a meta-analysis of epidemiological studies, PLoS One. 9, e89288.

Chlebowski, R.T., Rohan, T.E., Manson, J.E., Aragaki, A.K., Kaunitz, A., Stefanick, M.L., Simon, M.S., Johnson, K.C., Wectawski-Wende, J., O’Sullivan M.J., et al., 2015. Breast Cancer After Use of Estrogen Plus Progestin and Estrogen Alone: Analyses of Data From 2 Women's Health Initiative Randomized Clinical Trials, JAMA Oncol. doi:10.1001/jamaoncol.2015.0494.

Chobert, M.N., Barouki, R., Finidori, J., Aggerbeck, M., Hanoune, J., Philibert, D. and Deraedt, R., 1983. Antiglucocorticoid properties of RU 38486 in a differentiated hepatoma cell line, Biochem Pharmacol. 32, 3481-3.

Coates, A.S., Keshaviah, A., Thurlimann, B., Mouridsen, H., Mauriac, L., Forbes, J.F., Paridaens, R., Castiglione-Gertsch, M., Gelber, R.D., Colleoni, M. et al., 2007. Five years of letrozole compared with tamoxifen as initial adjuvant therapy for postmenopausal women with endocrine-responsive early breast cancer: update of study BIG 1-98, J Clin Oncol. 25, 486-92. 
Coombes, R.C., Goss, P., Dowsett, M., Gazet, J.C. and Brodie, A., 1984. 4-

Hydroxyandrostenedione in treatment of postmenopausal patients with advanced breast cancer, Lancet. 2, 1237-9.

Coombes, R.C., Hall, E., Gibson, L.J., Paridaens, R., Jassem, J., Delozier, T., Jones, S.E., Alvarez, I., Bertelli, G., Ortmann, O. et al., 2004. A randomized trial of exemestane after two to three years of tamoxifen therapy in postmenopausal women with primary breast cancer, N Engl J Med. 350, 1081-92.

Cummings, F.J., Gray, R., Davis, T.E., Tormey, D.C., Harris, J.E., Falkson, G. and Arseneau, J., 1985. Adjuvant tamoxifen treatment of elderly women with stage II breast cancer. A double-blind comparison with placebo, Ann Intern Med. 103, 324-9.

Cummings, S.R., Eckert, S., Krueger, K.A., Grady, D., Powles, T.J., Cauley, J.A., Norton, L., Nickelsen, T., Bjarnason, N.H., Morrow, M. et al., 1999. The effect of raloxifene on risk of breast cancer in postmenopausal women: results from the MORE randomized trial. Multiple Outcomes of Raloxifene Evaluation, JAMA. 281, 2189-97.

Cuzick, J. and Baum, M., 1985. Tamoxifen and contralateral breast cancer, Lancet. 2, 282.

Cuzick, J., Forbes, J.F., Sestak, I., Cawthorn, S., Hamed, H., Holli, K., Howell, A. and International Breast Cancer Intervention Study, I.I., 2007. Long-term results of tamoxifen prophylaxis for breast cancer--96-month follow-up of the randomized IBIS-I trial, J Natl Cancer Inst. 99, 272-82.

Cuzick, J., Sestak, I., Baum, M., Buzdar, A., Howell, A., Dowsett, M., Forbes, J.F. and investigators, A.L., 2010. Effect of anastrozole and tamoxifen as adjuvant treatment for early-stage breast cancer: 10-year analysis of the ATAC trial, Lancet Oncol. 11, 1135-41.

Davies, C., Pan, H., Godwin, J., Gray, R., Arriagada, R., Raina, V., Abraham, M., Medeiros Alencar, V.H., Badran, A., Bonfill, X. et al., 2013. Long-term effects of continuing adjuvant tamoxifen to 10 years versus stopping at 5 years after diagnosis of oestrogen receptor-positive breast cancer: ATLAS, a randomised trial, Lancet. 381, 805-16.

Delozier, T., Julien, J.P., Juret, P., Veyret, C., Couette, J.E., Graic, Y., Ollivier, J.M. and de Ranieri, E., 1986. Adjuvant tamoxifen in postmenopausal breast cancer: preliminary results of a randomized trial, Breast Cancer Res Treat. 7, 105-9.

Di Leo, A., Jerusalem, G., Petruzelka, L., Torres, R., Bondarenko, I.N., Khasanov, R., Verhoeven, D., Pedrini, J.L., Smirnova, I., Lichinitser, M.R. et al., 2014. Final overall survival: fulvestrant $500 \mathrm{mg}$ vs $250 \mathrm{mg}$ in the randomized CONFIRM trial, J Natl Cancer Inst. 106, djt337.

Dowsett, M., Cuzick, J., Ingle, J., Coates, A., Forbes, J., Bliss, J., Buyse, M., Baum, M., Buzdar, A., Colleoni, M. et al., 2010. Meta-analysis of breast cancer outcomes in adjuvant trials of aromatase inhibitors versus tamoxifen, J Clin Oncol. 28, 509-18.

DuSell, C.D., Umetani, M., Shaul, P.W., Mangelsdorf, D.J. and McDonnell, D.P., 2008. 27hydroxycholesterol is an endogenous selective estrogen receptor modulator, Mol Endocrinol. 22, 65-77.

DuSell, C.D., Nelson, E.R., Wang, X., Abdo, J., Modder, U.I., Umetani, M., Gesty-Palmer, D., Javitt, N.B., Khosla, S. and McDonnell, D.P., 2010. The endogenous selective estrogen receptor modulator 27-hydroxycholesterol is a negative regulator of bone homeostasis, Endocrinology. 151, 3675-85.

EBCTCG, 1998. Tamoxifen for early breast cancer: an overview of the randomised trials., Lancet. 351, 1451-67. 
EBCTCG, 2005. Effects of chemotherapy and hormonal therapy for early breast cancer on recurrence and 15-year survival: an overview of the randomised trials, Lancet. 365, 1687717.

EBCTCG, 2011. Relevance of breast cancer hormone receptors and other factors to the efficacy of adjuvant tamoxifen: patient-level meta-analysis of randomised trials, Lancet. 378, 77184.

Ellis, M.J., Gao, F., Dehdashti, F., Jeffe, D.B., Marcom, P.K., Carey, L.A., Dickler, M.N., Silverman, P., Fleming, G.F., Kommareddy, A. et al., 2009. Lower-dose vs high-dose oral estradiol therapy of hormone receptor-positive, aromatase inhibitor-resistant advanced breast cancer: a phase 2 randomized study, JAMA. 302, 774-80.

Fagan, D.H., Uselman, R.R., Sachdev, D. and Yee, D., 2012. Acquired resistance to tamoxifen is associated with loss of the type I insulin-like growth factor receptor: implications for breast cancer treatment, Cancer Res. 72, 3372-80.

Falkson, H.C., Gray, R., Wolberg, W.H., Gillchrist, K.W., Harris, J.E., Tormey, D.C. and Falkson, G., 1990. Adjuvant trial of 12 cycles of CMFPT followed by observation or continuous tamoxifen versus four cycles of CMFPT in postmenopausal women with breast cancer: an Eastern Cooperative Oncology Group phase III study, J Clin Oncol. 8, 599-607.

Fan, P., Wang, J., Santen, R.J. and Yue, W., 2007. Long-term treatment with tamoxifen facilitates translocation of estrogen receptor alpha out of the nucleus and enhances its interaction with EGFR in MCF-7 breast cancer cells, Cancer Res. 67, 1352-60.

Fan, P., McDaniel, R.E., Kim, H.R., Clagett, D., Haddad, B. and Jordan, V.C., 2012. Modulating therapeutic effects of the c-Src inhibitor via oestrogen receptor and human epidermal growth factor receptor 2 in breast cancer cell lines, Eur J Cancer. 48, 3488-98.

Fan, P., Griffith, O.L., Agboke, F.A., Anur, P., Zou, X., McDaniel, R.E., Creswell, K., Kim, S.H., Katzenellenbogen, J.A., Gray, J.W. et al., 2013. c-Src modulates estrogen-induced stress and apoptosis in estrogen-deprived breast cancer cells, Cancer Res. 73, 4510-20.

Fan, P., Cunliffe, H.E., Griffith, O.L., Agboke, F.A., Ramos, P., Gray, J.W. and Jordan, V.C., 2014a. Identification of gene regulation patterns underlying both oestrogen- and tamoxifen-stimulated cell growth through global gene expression profiling in breast cancer cells, Eur J Cancer. 50, 2877-86.

Fan, P., Agboke, F.A., Cunliffe, H.E., Ramos, P. and Jordan, V.C., 2014b. A molecular model for the mechanism of acquired tamoxifen resistance in breast cancer, Eur J Cancer. 50, 2866-76.

Fan, P., Agboke, F.A., McDaniel, R.E., Sweeney, E.E., Zou, X., Creswell, K. and Jordan, V.C., 2014c. Inhibition of c-Src blocks oestrogen-induced apoptosis and restores oestrogenstimulated growth in long-term oestrogen-deprived breast cancer cells, Eur J Cancer. 50, 457-68.

Feng, W., Webb, P., Nguyen, P., Liu, X., Li, J., Karin, M. and Kushner, P.J., 2001. Potentiation of estrogen receptor activation function 1 (AF-1) by Src/JNK through a serine 118independent pathway, Mol Endocrinol. 15, 32-45.

Fisher, B., Redmond, C., Brown, A., Fisher, E.R., Wolmark, N., Bowman, D., Plotkin, D., Wolter, J., Bornstein, R., Legault-Poisson, S. et al., 1986. Adjuvant chemotherapy with and without tamoxifen in the treatment of primary breast cancer: 5-year results from the National Surgical Adjuvant Breast and Bowel Project Trial, J Clin Oncol. 4, 459-71. 
Fisher, B., Brown, A., Wolmark, N., Redmond, C., Wickerham, D.L., Wittliff, J., Dimitrov, N., Legault-Poisson, S., Schipper, H. and Prager, D., 1987. Prolonging tamoxifen therapy for primary breast cancer. Findings from the National Surgical Adjuvant Breast and Bowel Project clinical trial, Ann Intern Med. 106, 649-54.

Fisher, B., Dignam, J., Bryant, J., DeCillis, A., Wickerham, D.L., Wolmark, N., Costantino, J., Redmond, C., Fisher, E.R., Bowman, D.M. et al., 1996. Five versus more than five years of tamoxifen therapy for breast cancer patients with negative lymph nodes and estrogen receptor-positive tumors, J Natl Cancer Inst. 88, 1529-42.

Fisher, B., Costantino, J.P., Wickerham, D.L., Redmond, C.K., Kavanah, M., Cronin, W.M., Vogel, V., Robidoux, A., Dimitrov, N., Atkins, J. et al., 1998. Tamoxifen for prevention of breast cancer: report of the National Surgical Adjuvant Breast and Bowel Project P-1 Study, J Natl Cancer Inst. 90, 1371-88.

Fisher, B., Costantino, J.P., Wickerham, D.L., Cecchini, R.S., Cronin, W.M., Robidoux, A., Bevers, T.B., Kavanah, M.T., Atkins, J.N., Margolese, R.G. et al., 2005. Tamoxifen for the prevention of breast cancer: current status of the National Surgical Adjuvant Breast and Bowel Project P-1 study, J Natl Cancer Inst. 97, 1652-62.

Folca, P.J., Glascock, R.F. and Irvine, W.T., 1961. Studies with tritium-labelled hexoestrol in advanced breast cancer. Comparison of tissue accumulation of hexoestrol with response to bilateral adrenalectomy and oophorectomy, Lancet. 2, 796-8.

Forbes, J.F., Cuzick, J., Buzdar, A., Howell, A., Tobias, J.S. and Baum, M., 2008. Effect of anastrozole and tamoxifen as adjuvant treatment for early-stage breast cancer: 100-month analysis of the ATAC trial, Lancet Oncol. 9, 45-53.

Fornander, T., Rutqvist, L.E., Cedermark, B., Glas, U., Mattsson, A., Silfversward, C., Skoog, L., Somell, A., Theve, T., Wilking, N. et al., 1989. Adjuvant tamoxifen in early breast cancer: occurrence of new primary cancers, Lancet. 1, 117-20.

Glascock, R.F. and Hoekstra, W.G., 1959. Selective accumulation of tritium-labelled hexoestrol by the reproductive organs of immature female goats and sheep, Biochem J. 72, 673-82.

Goss, P.E., Ingle, J.N., Martino, S., Robert, N.J., Muss, H.B., Piccart, M.J., Castiglione, M., Tu, D., Shepherd, L.E., Pritchard, K.I. et al., 2003. A randomized trial of letrozole in postmenopausal women after five years of tamoxifen therapy for early-stage breast cancer, N Engl J Med. 349, 1793-802.

Goss, P.E., Ingle, J.N., Martino, S., Robert, N.J., Muss, H.B., Piccart, M.J., Castiglione, M., Tu, D., Shepherd, L.E., Pritchard, K.I. et al., 2005. Randomized trial of letrozole following tamoxifen as extended adjuvant therapy in receptor-positive breast cancer: updated findings from NCIC CTG MA.17, J Natl Cancer Inst. 97, 1262-71.

Gottardis, M.M., Robinson, S.P., Satyaswaroop, P.G. and Jordan, V.C., 1988. Contrasting actions of tamoxifen on endometrial and breast tumor growth in the athymic mouse, Cancer Res. 48, 812-5.

Gottardis, M.M. and Jordan, V.C., 1988. Development of Tamoxifen-stimulated Growth of MCF-7 Tumors in Athymic Mice after Long-Term Antiestrogen Administration, Cancer Research. 48, 5183-5187.

Gottardis, M.M., Wagner, R.J., Borden, E.C. and Jordan, V.C., 1989a. Differential ability of antiestrogens to stimulate breast cancer cell (MCF-7) growth in vivo and in vitro, Cancer Res. 49, 4765-9. 
Gottardis, M.M., Jiang, S.Y., Jeng, M.H. and Jordan, V.C., 1989b. Inhibition of tamoxifenstimulated growth of an MCF-7 tumor variant in athymic mice by novel steroidal antiestrogens, Cancer Res. 49, 4090-3.

Gradishar, W.J. and Jordan, V.C., 1997. Clinical potential of new antiestrogens, J Clin Oncol. $15,840-52$.

Greene, G.L., Gilna, P., Waterfield, M., Baker, A., Hort, Y. and Shine, J., 1986. Sequence and expression of human estrogen receptor complementary DNA, Science. 231, 1150-4.

Haddow, A., Watkinson, J.M. and Paterson, E., 1944. Influence of synthetic oestrogens upon advanced malignant disease., British Medical Journal. 393-398.

Haddow, A., 1970. David A. Karnofsky memorial lecture. Thoughts on chemical therapy, Cancer. 26, 737-54.

Haldosen, L.A., Zhao, C. and Dahlman-Wright, K., 2014. Estrogen receptor beta in breast cancer, Mol Cell Endocrinol. 382, 665-72.

Hardell, L., 1988. Tamoxifen as risk factor for carcinoma of corpus uteri, Lancet. 2, 563.

Harper, M.J. and Walpole, A.L., 1967. A new derivative of triphenylethylene: effect on implantation and mode of action in rats, J Reprod Fertil. 13, 101-19.

Howell, A., Dodwell, D.J., Anderson, H. and Redford, J., 1992. Response after withdrawal of tamoxifen and progestogens in advanced breast cancer, Ann Oncol. 3, 611-7.

Howell, A., Robertson, J.F., Quaresma Albano, J., Aschermannova, A., Mauriac, L., Kleeberg, U.R., Vergote, I., Erikstein, B., Webster, A. and Morris, C., 2002. Fulvestrant, formerly ICI 182,780, is as effective as anastrozole in postmenopausal women with advanced breast cancer progressing after prior endocrine treatment, J Clin Oncol. 20, 3396-403.

Howell, A., Cuzick, J., Baum, M., Buzdar, A., Dowsett, M., Forbes, J.F., Hoctin-Boes, G., Houghton, J., Locker, G.Y., Tobias, J.S. et al., 2005. Results of the ATAC (Arimidex, Tamoxifen, Alone or in Combination) trial after completion of 5 years' adjuvant treatment for breast cancer, Lancet. 365, 60-2.

Huang, H.J., Norris, J.D. and McDonnell, D.P., 2002. Identification of a negative regulatory surface within estrogen receptor alpha provides evidence in support of a role for corepressors in regulating cellular responses to agonists and antagonists, Mol Endocrinol. $16,1778-92$.

Hutcheson, I.R., Knowlden, J.M., Madden, T.A., Barrow, D., Gee, J.M., Wakeling, A.E. and Nicholson, R.I., 2003. Oestrogen receptor-mediated modulation of the EGFR/MAPK pathway in tamoxifen-resistant MCF-7 cells, Breast Cancer Res Treat. 81, 81-93.

Jeng, M.H., Parker, C.J. and Jordan, V.C., 1992. Estrogenic potential of progestins in oral contraceptives to stimulate human breast cancer cell proliferation, Cancer Res. 52, 653946.

Jeng, M.H., Jiang, S.Y. and Jordan, V.C., 1994. Paradoxical regulation of estrogen-dependent growth factor gene expression in estrogen receptor (ER)-negative human breast cancer cells stably expressing ER, Cancer Lett. 82, 123-8.

Jensen, E.V. and Jacobson, H.I., 1962. Basic guides to the mechanism of estrogen action, Recent Prog Horm Res. 18, 387.

Jensen, E.V., Block, G.E., Smith, S., Kyser, K. and DeSombre, E.R., 1971. Estrogen receptors and breast cancer response to adrenalectomy, Natl Cancer Inst Monogr. 34, 55-70.

Jensen, E.V. and Jordan, V.C., 2003. The estrogen receptor: a model for molecular medicine, Clin Cancer Res. 9, 1980-9. 
Jeselsohn, R., Yelensky, R., Buchwalter, G., Frampton, G., Meric-Bernstam, F., GonzalezAngulo, A.M., Ferrer-Lozano, J., Perez-Fidalgo, J.A., Cristofanilli, M., Gomez, H. et al., 2014. Emergence of constitutively active estrogen receptor-alpha mutations in pretreated advanced estrogen receptor-positive breast cancer, Clin Cancer Res. 20, 1757-67.

Jiang, S.Y. and Jordan, V.C., 1992. Growth regulation of estrogen receptor-negative breast cancer cells transfected with complementary DNAs for estrogen receptor, J Natl Cancer Inst. 84, 580-91.

Jordan, V.C., 1978. Use of DMBA-induced rat mammary carcinoma system for the evaluation of tamoxifen as a potantial adjuvant therapy., Rev Endocrine Relat Cancer. 49-55 (October supplement).

Jordan, V.C., Dix, C.J. and Allen, K.E., 1979. The effectiveness of leng term tamoxifen treatment in a laboratory model for adjuvant hormone therapy of breast cancer, in: Salmon, S.E. and Jones, S.E. (Eds.), Adjuvant Therapy of Cancer II. Grune \& Stratton Inc., New York, pp. 19-26.

Jordan, V.C. and Allen, K.E., 1980. Evaluation of the antitumour activity of the non-steroidal antioestrogen monohydroxytamoxifen in the DMBA-induced rat mammary carcinoma model, Eur J Cancer. 16, 239-51.

Jordan, V.C., 1983. Laboratory studies to develop general principles for the adjuvant treatment of breast cancer with antiestrogens: problems and potential for future clinical applications, Breast Cancer Res Treat. 3 Suppl, S73-86.

Jordan, V.C., 1984. Biochemical pharmacology of antiestrogen action, Pharmacol Rev. 36, 24576.

Jordan, V.C., Lieberman, M.E., Cormier, E., Koch, R., Bagley, J.R. and Ruenitz, P.C., 1984. Structural requirements for the pharmacological activity of nonsteroidal antiestrogens in vitro, Mol Pharmacol. 26, 272-8.

Jordan, V.C., Koch, R., Mittal, S. and Schneider, M.R., 1986. Oestrogenic and antioestrogenic actions in a series of triphenylbut-1-enes: modulation of prolactin synthesis in vitro, $\mathrm{Br} \mathrm{J}$ Pharmacol. 87, 217-23.

Jordan, V.C., Phelps, E. and Lindgren, J.U., 1987. Effects of anti-estrogens on bone in castrated and intact female rats, Breast Cancer Res Treat. 10, 31-5.

Jordan, V.C., 1987. Laboratory models of breast cancer to aid the elucidation of antiestrogen action, J Lab Clin Med. 109, 267-77.

Jordan, V.C., 1988a. Chemosuppression of breast cancer with tamoxifen: laboratory evidence and future clinical investigations, Cancer Invest. 6, 589-95.

Jordan, V.C., Wolf, M.F., Mirecki, D.M., Whitford, D.A. and Welshons, W.V., 1988. Hormone receptor assays: clinical usefulness in the management of carcinoma of the breast, Crit Rev Clin Lab Sci. 26, 97-152.

Jordan, V.C., 1988b. Tamoxifen and endometrial cancer, Lancet. 2, 1019.

Jordan, V.C. and Koch, R., 1989. Regulation of prolactin synthesis in vitro by estrogenic and antiestrogenic derivatives of estradiol and estrone, Endocrinology. 124, 1717-26.

Jordan, V.C., 1998. Antiestrogenic action of raloxifene and tamoxifen: today and tomorrow, J Natl Cancer Inst. 90, 967-71.

Jordan, V.C., Schafer, J.M., Levenson, A.S., Liu, H., Pease, K.M., Simons, L.A. and Zapf, J.W., 2001. Molecular classification of estrogens, Cancer Res. 61, 6619-23.

Jordan, V.C., 2001. Selective estrogen receptor modulation: a personal perspective, Cancer Res. 61, 5683-7. 
Jordan, V.C., 2003a. Tamoxifen: a most unlikely pioneering medicine, Nat Rev Drug Discov. 2, 205-13.

Jordan, V.C., 2003b. Antiestrogens and selective estrogen receptor modulators as multifunctional medicines. 1. Receptor interactions, J Med Chem. 46, 883-908.

Jordan, V.C., 2003c. Antiestrogens and selective estrogen receptor modulators as multifunctional medicines. 2. Clinical considerations and new agents, J Med Chem. 46, 1081-111.

Jordan, V.C., 2004. Selective estrogen receptor modulation: concept and consequences in cancer, Cancer Cell. 5, 207-13.

Jordan, V.C., 2006. Tamoxifen (ICI46,474) as a targeted therapy to treat and prevent breast cancer, Br J Pharmacol. 147 Suppl 1, S269-76.

Jordan, V.C. and Brodie, A.M., 2007. Development and evolution of therapies targeted to the estrogen receptor for the treatment and prevention of breast cancer, Steroids. 72, 7-25.

Jordan, V.C., 2007. Chemoprevention of breast cancer with selective oestrogen-receptor modulators, Nat Rev Cancer. 7, 46-53.

Jordan, V.C. and O'Malley, B.W., 2007. Selective estrogen-receptor modulators and antihormonal resistance in breast cancer, J Clin Oncol. 25, 5815-24.

Jordan, V.C., 2008a. Tamoxifen: catalyst for the change to targeted therapy, Eur J Cancer. 44, $30-8$

Jordan, V.C., 2008b. The 38th David A. Karnofsky lecture: the paradoxical actions of estrogen in breast cancer--survival or death?, J Clin Oncol. 26, 3073-82.

Jordan, V.C. and Ford, L.G., 2011. Paradoxical clinical effect of estrogen on breast cancer risk: a "new" biology of estrogen-induced apoptosis, Cancer Prev Res (Phila). 4, 633-7.

Jordan, V.C., 2014a. Tamoxifen as the first targeted long-term adjuvant therapy for breast cancer, Endocr Relat Cancer. 21, R235-46.

Jordan, V.C., 2014b. Linking estrogen-induced apoptosis with decreases in mortality following long-term adjuvant tamoxifen therapy, J Natl Cancer Inst. 106, doi: 10.1093/jnci/dju296.

Jordan, V.C., 2014c. Avoiding the bad and enhancing the good of soy supplements in breast cancer, J Natl Cancer Inst. 106, doi: 10.1093/jnci/dju233.

Jordan, V.C., 2015a. Proven value of translational research with appropriate animal models to advance breast cancer treatment and save lives: the tamoxifen tale, Br J Clin Pharmacol. $79,254-67$.

Jordan, V.C., 2015b. The new biology of estrogen-induced apoptosis applied to treat and prevent breast cancer, Endocr Relat Cancer. 22, R1-31.

Jordan, V.C., Curpan, R.F. and Maximov, P.Y., 2015. Estrogen Receptor (ER) Mutations Found in Breast Cancer Metastases Integrated with the Molecular Pharmacology of Selective ER Modulators (SERMs). J Natl Cancer Inst. 107 (6), doi:10.1093/jnci/djv075.

Kalaitzidis, D. and Gilmore, T.D., 2005. Transcription factor cross-talk: the estrogen receptor and NF-kappaB, Trends Endocrinol Metab. 16, 46-52.

Kennedy, B.J. and Nathanson, I.T., 1953. Effects of intensive sex steroid hormone therapy in advanced breast cancer, J Am Med Assoc. 152, 1135-41.

Klinge, C.M., 2001. Estrogen receptor interaction with estrogen response elements, Nucleic Acids Res. 29, 2905-19.

Knowlden, J.M., Hutcheson, I.R., Barrow, D., Gee, J.M. and Nicholson, R.I., 2005. Insulin-like growth factor-I receptor signaling in tamoxifen-resistant breast cancer: a supporting role to the epidermal growth factor receptor, Endocrinology. 146, 4609-18. 
Koide, A., Zhao, C., Naganuma, M., Abrams, J., Deighton-Collins, S., Skafar, D.F. and Koide, S., 2007. Identification of regions within the F domain of the human estrogen receptor alpha that are important for modulating transactivation and protein-protein interactions, Mol Endocrinol. 21, 829-42.

Koubovec, D., Ronacher, K., Stubsrud, E., Louw, A. and Hapgood, J.P., 2005. Synthetic progestins used in HRT have different glucocorticoid agonist properties, Mol Cell Endocrinol. 242, 23-32.

Kuiper, G.G., Enmark, E., Pelto-Huikko, M., Nilsson, S. and Gustafsson, J.A., 1996. Cloning of a novel receptor expressed in rat prostate and ovary, Proc Natl Acad Sci U S A. 93, 592530.

Kumar, V., Green, S., Stack, G., Berry, M., Jin, J.R. and Chambon, P., 1987. Functional domains of the human estrogen receptor, Cell. 51, 941-51.

Lacassagne, A., 1936a. A comparative study of the carcinogenic action of certain oestrogenic hormones. , Am J Cancer. 28, 735-740.

Lacassagne, A., 1936b. Hormonal pathogenesis of adenocarcinoma of the breast., Am J Cancer. 27, 217-28.

Lannigan, D.A., 2003. Estrogen receptor phosphorylation, Steroids. 68, 1-9.

Lathrop, A.E. and Loeb, L., 1916. Further investigations on the origin of tumors in mice. III. On the part played by internal secretion in the spontaneous development of tumors, J Cancer Res. 1, 1-19.

Lee, E.S., Schafer, J.M., Yao, K., England, G., O'Regan, R.M., De Los Reyes, A. and Jordan, V.C., 2000. Cross-resistance of triphenylethylene-type antiestrogens but not ICI 182,780 in tamoxifen-stimulated breast tumors grown in athymic mice, Clin Cancer Res. 6, 48939.

Lerner, L.J. and Jordan, V.C., 1990. Development of antiestrogens and their use in breast cancer: eighth Cain memorial award lecture, Cancer Res. 50, 4177-89.

Levenson, A.S., Catherino, W.H. and Jordan, V.C., 1997. Estrogenic activity is increased for an antiestrogen by a natural mutation of the estrogen receptor, J Steroid Biochem Mol Biol. 60, 261-8.

Levenson, A.S. and Jordan, V.C., 1998. The key to the antiestrogenic mechanism of raloxifene is amino acid 351 (aspartate) in the estrogen receptor, Cancer Res. 58, 1872-5.

Levenson, A.S., Tonetti, D.A. and Jordan, V.C., 1998. The oestrogen-like effect of 4hydroxytamoxifen on induction of transforming growth factor alpha mRNA in MDAMB-231 breast cancer cells stably expressing the oestrogen receptor, Br J Cancer. 77, 1812-9.

Levenson, A.S., MacGregor Schafer, J.I., Bentrem, D.J., Pease, K.M. and Jordan, V.C., 2001. Control of the estrogen-like actions of the tamoxifen-estrogen receptor complex by the surface amino acid at position 351, J Steroid Biochem Mol Biol. 76, 61-70.

Lewis, J.S., Osipo, C., Meeke, K. and Jordan, V.C., 2005a. Estrogen-induced apoptosis in a breast cancer model resistant to long-term estrogen withdrawal, J Steroid Biochem Mol Biol. 94, 131-41.

Lewis, J.S., Meeke, K., Osipo, C., Ross, E.A., Kidawi, N., Li, T., Bell, E., Chandel, N.S. and Jordan, V.C., 2005b. Intrinsic mechanism of estradiol-induced apoptosis in breast cancer cells resistant to estrogen deprivation, J Natl Cancer Inst. 97, 1746-59. 
Li, S., Shen, D., Shao, J., Crowder, R., Liu, W., Prat, A., He, X., Liu, S., Hoog, J., Lu, C. et al., 2013. Endocrine-Therapy-Resistant ESR1 Variants Revealed by Genomic

Characterization of Breast-Cancer-Derived Xenografts, Cell Rep. 4, 1116-30.

Lieberman, M.E., Jordan, V.C., Fritsch, M., Santos, M.A. and Gorski, J., 1983a. Direct and reversible inhibition of estradiol-stimulated prolactin synthesis by antiestrogens in vitro, J Biol Chem. 258, 4734-40.

Lieberman, M.E., Gorski, J. and Jordan, V.C., 1983b. An estrogen receptor model to describe the regulation of prolactin synthesis by antiestrogens in vitro, J Biol Chem. 258, 4741-5.

Liu, H., Lee, E.S., Deb Los Reyes, A., Zapf, J.W. and Jordan, V.C., 2001. Silencing and reactivation of the selective estrogen receptor modulator-estrogen receptor alpha complex, Cancer Res. 61, 3632-9.

Liu, H., Park, W.C., Bentrem, D.J., McKian, K.P., Reyes Ade, L., Loweth, J.A., Schafer, J.M., Zapf, J.W. and Jordan, V.C., 2002. Structure-function relationships of the raloxifeneestrogen receptor-alpha complex for regulating transforming growth factor-alpha expression in breast cancer cells, J Biol Chem. 277, 9189-98.

Liu, H., Lee, E.S., Gajdos, C., Pearce, S.T., Chen, B., Osipo, C., Loweth, J., McKian, K., De Los Reyes, A., Wing, L. et al., 2003. Apoptotic action of 17beta-estradiol in raloxifeneresistant MCF-7 cells in vitro and in vivo, J Natl Cancer Inst. 95, 1586-97.

Lonard, D.M., Tsai, S.Y. and O'Malley, B.W., 2004. Selective estrogen receptor modulators 4hydroxytamoxifen and raloxifene impact the stability and function of SRC-1 and SRC-3 coactivator proteins, Mol Cell Biol. 24, 14-24.

Lonning, P.E., Taylor, P.D., Anker, G., Iddon, J., Wie, L., Jorgensen, L.M., Mella, O. and Howell, A., 2001. High-dose estrogen treatment in postmenopausal breast cancer patients heavily exposed to endocrine therapy, Breast Cancer Res Treat. 67, 111-6.

Lonning, P.E., 2009. Additive endocrine therapy for advanced breast cancer - back to the future, Acta Oncol. 48, 1092-101.

Love, R.R., Newcomb, P.A., Wiebe, D.A., Surawicz, T.S., Jordan, V.C., Carbone, P.P. and DeMets, D.L., 1990. Effects of tamoxifen therapy on lipid and lipoprotein levels in postmenopausal patients with node-negative breast cancer, J Natl Cancer Inst. 82, 1327 32.

Love, R.R., Wiebe, D.A., Newcomb, P.A., Cameron, L., Leventhal, H., Jordan, V.C., Feyzi, J. and DeMets, D.L., 1991. Effects of tamoxifen on cardiovascular risk factors in postmenopausal women, Ann Intern Med. 115, 860-4.

Love, R.R., Mazess, R.B., Barden, H.S., Epstein, S., Newcomb, P.A., Jordan, V.C., Carbone, P.P. and DeMets, D.L., 1992. Effects of tamoxifen on bone mineral density in postmenopausal women with breast cancer, N Engl J Med. 326, 852-6.

MacGregor Schafer, J., Liu, H., Bentrem, D.J., Zapf, J.W. and Jordan, V.C., 2000. Allosteric silencing of activating function 1 in the 4-hydroxytamoxifen estrogen receptor complex is induced by substituting glycine for aspartate at amino acid 351, Cancer Res. 60, 5097 105.

MacGregor Schafer, J., Liu, H., Levenson, A.S., Horiguchi, J., Chen, Z. and Jordan, V.C., 2001. Estrogen receptor alpha mediated induction of the transforming growth factor alpha gene by estradiol and 4-hydroxytamoxifen in MDA-MB-231 breast cancer cells, J Steroid Biochem Mol Biol. 78, 41-50.

Martino, S., Cauley, J.A., Barrett-Connor, E., Powles, T.J., Mershon, J., Disch, D., Secrest, R.J., Cummings, S.R. and Investigators, C., 2004. Continuing outcomes relevant to Evista: 
breast cancer incidence in postmenopausal osteoporotic women in a randomized trial of raloxifene, J Natl Cancer Inst. 96, 1751-61.

Massarweh, S., Osborne, C.K., Creighton, C.J., Qin, L., Tsimelzon, A., Huang, S., Weiss, H., Rimawi, M. and Schiff, R., 2008. Tamoxifen resistance in breast tumors is driven by growth factor receptor signaling with repression of classic estrogen receptor genomic function, Cancer Res. 68, 826-33.

Maximov, P.Y., Myers, C.B., Curpan, R.F., Lewis-Wambi, J.S. and Jordan, V.C., 2010. Structure-function relationships of estrogenic triphenylethylenes related to endoxifen and 4-hydroxytamoxifen, J Med Chem. 53, 3273-83.

Maximov, P.Y., Sengupta, S., Lewis-Wambi, J.S., Kim, H.R., Curpan, R.F. and Jordan, V.C., 2011. The Conformation of the Estrogen Receptor Directs Estrogen-Induced Apoptosis in Breast Cancer: A Hypothesis, Horm Mol Biol Clin Investig. 5, 27-34.

Maximov, P.Y., McDaniel, R.E. and Jordan, V.C., 2013a. Tamoxifen: Pioneering Medicine in Breast Cancer., Springer, Basel.

Maximov, P.Y., Lee, T.M. and Jordan, V.C., 2013b. The discovery and development of selective estrogen receptor modulators (SERMs) for clinical practice, Curr Clin Pharmacol. 8, 13555.

Maximov, P.Y., Fernandes, D.J., McDaniel, R.E., Myers, C.B., Curpan, R.F. and Jordan, V.C., 2014. Influence of the length and positioning of the antiestrogenic side chain of endoxifen and 4-hydroxytamoxifen on gene activation and growth of estrogen receptor positive cancer cells, J Med Chem. 57, 4569-83.

McDaniel, R.E., Maximov, P.Y. and Jordan, V.C., 2013. Estrogen-mediated mechanisms to control the growth and apoptosis of breast cancer cells: a translational research success story, Vitam Horm. 93, 1-49.

McGuire, W.L., Carbone, P.P. and Vollmer, E.P., 1975. Estrogen Receptors in Human Breast Cancer., Raven Press, New York.

McKenna, N.J. and O'Malley, B.W., 2002. Minireview: nuclear receptor coactivators--an update, Endocrinology. 143, 2461-5.

Merenbakh-Lamin, K., Ben-Baruch, N., Yeheskel, A., Dvir, A., Soussan-Gutman, L., Jeselsohn, R., Yelensky, R., Brown, M., Miller, V.A., Sarid, D. et al., 2013. D538G Mutation in Estrogen Receptor-alpha: A Novel Mechanism for Acquired Endocrine Resistance in Breast Cancer, Cancer Res. 73, 6856-64.

Montano, M.M., Muller, V., Trobaugh, A. and Katzenellenbogen, B.S., 1995. The carboxyterminal $\mathrm{F}$ domain of the human estrogen receptor: role in the transcriptional activity of the receptor and the effectiveness of antiestrogens as estrogen antagonists, Mol Endocrinol. 9, 814-25.

Murphy, C.S., Langan-Fahey, S.M., McCague, R. and Jordan, V.C., 1990. Structure-function relationships of hydroxylated metabolites of tamoxifen that control the proliferation of estrogen-responsive T47D breast cancer cells in vitro, Mol Pharmacol. 38, 737-43.

Murphy, C.S., Parker, C.J., McCague, R. and Jordan, V.C., 1991. Structure-activity relationships of nonisomerizable derivatives of tamoxifen: importance of hydroxyl group and side chain positioning for biological activity, Mol Pharmacol. 39, 421-8.

Nagata, C., Mizoue, T., Tanaka, K., Tsuji, I., Tamakoshi, A., Matsuo, K., Wakai, K., Inoue, M., Tsugane, S., Sasazuki, S. et al., 2014. Soy intake and breast cancer risk: an evaluation based on a systematic review of epidemiologic evidence among the Japanese population, Jpn J Clin Oncol. 44, 282-95. 
NATO, 1983. Controlled trial of tamoxifen as adjuvant agent in management of early breast cancer. Interim analysis at four years by Nolvadex Adjuvant Trial Organisation, Lancet. 1, 257-61.

NATO, 1985. Controlled trial of tamoxifen as single adjuvant agent in management of early breast cancer. Analysis at six years by Nolvadex Adjuvant Trial Organisation, Lancet. 1, 836-40.

Nelson, E.R., Wardell, S.E., Jasper, J.S., Park, S., Suchindran, S., Howe, M.K., Carver, N.J., Pillai, R.V., Sullivan, P.M., Sondhi, V. et al., 2013. 27-Hydroxycholesterol links hypercholesterolemia and breast cancer pathophysiology, Science. 342, 1094-8.

Norris, J.D., Paige, L.A., Christensen, D.J., Chang, C.Y., Huacani, M.R., Fan, D., Hamilton, P.T., Fowlkes, D.M. and McDonnell, D.P., 1999. Peptide antagonists of the human estrogen receptor, Science. 285, 744-6.

Obiorah, I. and Jordan, V.C., 2013. Scientific rationale for postmenopause delay in the use of conjugated equine estrogens among postmenopausal women that causes reduction in breast cancer incidence and mortality, Menopause. 20, 372-82.

Obiorah, I., Sengupta, S., Curpan, R. and Jordan, V.C., 2014a. Defining the conformation of the estrogen receptor complex that controls estrogen-induced apoptosis in breast cancer, Mol Pharmacol. 85, 789-99.

Obiorah, I., Sengupta, S., Fan, P. and Jordan, V.C., 2014b. Delayed triggering of oestrogen induced apoptosis that contrasts with rapid paclitaxel-induced breast cancer cell death, $\mathrm{Br}$ J Cancer. 110, 1488-96.

Obiorah, I.E., Fan, P. and Jordan, V.C., 2014c. Breast cancer cell apoptosis with phytoestrogens is dependent on an estrogen-deprived state, Cancer Prev Res (Phila). 7, 939-49.

Obiorah, I.E. and Jordan, V.C., 2014. Differences in the rate of oestrogen-induced apoptosis in breast cancer by oestradiol and the triphenylethylene bisphenol, Br J Pharmacol. 171, 4062-72.

Onate, S.A., Tsai, S.Y., Tsai, M.J. and O'Malley, B.W., 1995. Sequence and characterization of a coactivator for the steroid hormone receptor superfamily, Science. 270, 1354-7.

Osborne, C.K., Pippen, J., Jones, S.E., Parker, L.M., Ellis, M., Come, S., Gertler, S.Z., May, J.T., Burton, G., Dimery, I. et al., 2002. Double-blind, randomized trial comparing the efficacy and tolerability of fulvestrant versus anastrozole in postmenopausal women with advanced breast cancer progressing on prior endocrine therapy: results of a North American trial, J Clin Oncol. 20, 3386-95.

Osipo, C., Gajdos, C., Liu, H., Chen, B. and Jordan, V.C., 2003. Paradoxical action of fulvestrant in estradiol-induced regression of tamoxifen-stimulated breast cancer, J Natl Cancer Inst. 95, 1597-608.

Osipo, C., Meeke, K., Cheng, D., Weichel, A., Bertucci, A., Liu, H. and Jordan, V.C., 2007. Role for HER2/neu and HER3 in fulvestrant-resistant breast cancer, Int J Oncol. 30, 509-20.

Powles, T.J., Ashley, S., Tidy, A., Smith, I.E. and Dowsett, M., 2007. Twenty-year follow-up of the Royal Marsden randomized, double-blinded tamoxifen breast cancer prevention trial, J Natl Cancer Inst. 99, 283-90.

Ribeiro, G. and Palmer, M.K., 1983. Adjuvant tamoxifen for operable carcinoma of the breast: report of clinical trial by the Christie Hospital and Holt Radium Institute, Br Med J (Clin Res Ed). 286, 827-30.

Ribeiro, G. and Swindell, R., 1985. The Christie Hospital tamoxifen (Nolvadex) adjuvant trial for operable breast carcinoma--7-yr results, Eur J Cancer Clin Oncol. 21, 897-900. 
Robinson, D.R., Wu, Y.M., Vats, P., Su, F., Lonigro, R.J., Cao, X., Kalyana-Sundaram, S., Wang, R., Ning, Y., Hodges, L. et al., 2013. Activating ESR1 mutations in hormoneresistant metastatic breast cancer, Nat Genet. 45, 1446-51.

Robinson, S.P., Koch, R. and Jordan, V.C., 1988. In vitro estrogenic actions in rat and human cells of hydroxylated derivatives of D16726 (zindoxifene), an agent with known antimammary cancer activity in vivo, Cancer Res. 48, 784-7.

Rossouw, J.E., Anderson, G.L., Prentice, R.L., LaCroix, A.Z., Kooperberg, C., Stefanick, M.L., Jackson, R.D., Beresford, S.A., Howard, B.V., Johnson, K.C. et al., 2002. Risks and benefits of estrogen plus progestin in healthy postmenopausal women: principal results From the Women's Health Initiative randomized controlled trial, JAMA. 288, 321-33.

Sanchez, R., Nguyen, D., Rocha, W., White, J.H. and Mader, S., 2002. Diversity in the mechanisms of gene regulation by estrogen receptors, Bioessays. 24, 244-54.

Santen, R.J., Brodie, H., Simpson, E.R., Siiteri, P.K. and Brodie, A., 2009. History of aromatase: saga of an important biological mediator and therapeutic target, Endocr Rev. 30, 343-75.

Schafer, J.I., Liu, H., Tonetti, D.A. and Jordan, V.C., 1999. The interaction of raloxifene and the active metabolite of the antiestrogen EM-800 (SC 5705) with the human estrogen receptor, Cancer Res. 59, 4308-13.

Schwartz, J.A., Zhong, L., Deighton-Collins, S., Zhao, C. and Skafar, D.F., 2002. Mutations targeted to a predicted helix in the extreme carboxyl-terminal region of the human estrogen receptor-alpha alter its response to estradiol and 4-hydroxytamoxifen, J Biol Chem. 277, 13202-9.

SCTO, 1987. Adjuvant tamoxifen in the management of operable breast cancer: the Scottish Trial. , Lancet. 2, 171-5.

Sengupta, S., Obiorah, I., Maximov, P.Y., Curpan, R. and Jordan, V.C., 2013. Molecular mechanism of action of bisphenol and bisphenol A mediated by oestrogen receptor alpha in growth and apoptosis of breast cancer cells, Br J Pharmacol. 169, 167-78.

Shapiro, S., Kelly, J.P., Rosenberg, L., Kaufman, D.W., Helmrich, S.P., Rosenshein, N.B., Lewis, J.L., Jr., Knapp, R.C., Stolley, P.D. and Schottenfeld, D., 1985. Risk of localized and widespread endometrial cancer in relation to recent and discontinued use of conjugated estrogens, N Engl J Med. 313, 969-72.

Shiau, A.K., Barstad, D., Loria, P.M., Cheng, L., Kushner, P.J., Agard, D.A. and Greene, G.L., 1998. The structural basis of estrogen receptor/coactivator recognition and the antagonism of this interaction by tamoxifen, Cell. 95, 927-37.

Shike, M., Doane, A.S., Russo, L., Cabal, R., Reis-Filho, J.S., Gerald, W., Cody, H., Khanin, R., Bromberg, J. and Norton, L., 2014. The effects of soy supplementation on gene expression in breast cancer: a randomized placebo-controlled study, J Natl Cancer Inst. 106, doi: 10.1093/jnci/dju189.

Shou, J., Massarweh, S., Osborne, C.K., Wakeling, A.E., Ali, S., Weiss, H. and Schiff, R., 2004. Mechanisms of tamoxifen resistance: increased estrogen receptor-HER2/neu cross-talk in ER/HER2-positive breast cancer, J Natl Cancer Inst. 96, 926-35.

Skor, M.N., Wondel, E.L., Kocherginsky, M., Goyal, A., Hall, B.A., Cai, Y., Conzen, S.D., 2013. Glucocorticoid receptor antagonism as a novel therapy for triple-negative breast cancer, Clin Cancer Res. 19, 6163-72.

Sledge, G.W., Mamounas, E.P., Hortobagyi, G.N., Burstein, H.J., Goodwin, P.J. and Wolff, A.C., 2014. Past, present, and future challenges in breast cancer treatment, J Clin Oncol. 32, 1979-86. 
Smith, D.C., Prentice, R., Thompson, D.J. and Herrmann, W.L., 1975. Association of exogenous estrogen and endometrial carcinoma, N Engl J Med. 293, 1164-7.

Song, R.X., Mor, G., Naftolin, F., McPherson, R.A., Song, J., Zhang, Z., Yue, W., Wang, J. and Santen, R.J., 2001. Effect of long-term estrogen deprivation on apoptotic responses of breast cancer cells to 17beta-estradiol, J Natl Cancer Inst. 93, 1714-23.

Speroff, L., 2009. A Good Man, Gregory Goodwin Pincus: The Man, His Story, the Birth Control Pill., Armica Publishing Inc., Portland, Oergon.

Sweeney, E.E., Fan, P. and Jordan, V.C., 2014a. Mechanisms underlying differential response to estrogen-induced apoptosis in long-term estrogen-deprived breast cancer cells, Int J Oncol. 44, 1529-38.

Sweeney, E.E., Fan, P. and Jordan, V.C., 2014b. Molecular modulation of estrogen-induced apoptosis by synthetic progestins in hormone replacement therapy: an insight into the women's health initiative study, Cancer Res. 74, 7060-8.

Tate, A.C., Greene, G.L., DeSombre, E.R., Jensen, E.V. and Jordan, V.C., 1984a. Differences between estrogen- and antiestrogen-estrogen receptor complexes from human breast tumors identified with an antibody raised against the estrogen receptor, Cancer Res. 44, 1012-8.

Tate, A.C., Lieberman, M.E. and Jordan, V.C., 1984b. The inhibition of prolactin synthesis in $\mathrm{GH} 3$ rat pituitary tumor cells by monohydroxytamoxifen is associated with changes in the properties of the estrogen receptor, J Steroid Biochem. 20, 391-5.

Thurlimann, B., Keshaviah, A., Coates, A.S., Mouridsen, H., Mauriac, L., Forbes, J.F., Paridaens, R., Castiglione-Gertsch, M., Gelber, R.D., Rabaglio, M. et al., 2005. A comparison of letrozole and tamoxifen in postmenopausal women with early breast cancer, N Engl J Med. 353, 2747-57.

Toft, D. and Gorski, J., 1966. A receptor molecule for estrogens: isolation from the rat uterus and preliminary characterization, Proc Natl Acad Sci U S A. 55, 1574-81.

Toft, D., Shyamala, G. and Gorski, J., 1967. A receptor molecule for estrogens: studies using a cell-free system, Proc Natl Acad Sci U S A. 57, 1740-3.

Toy, W., Shen, Y., Won, H., Green, B., Sakr, R.A., Will, M., Li, Z., Gala, K., Fanning, S., King, T.A. et al., 2013. ESR1 ligand-binding domain mutations in hormone-resistant breast cancer, Nat Genet. 45, 1439-45.

Umetani, M., Domoto, H., Gormley, A.K., Yuhanna, I.S., Cummins, C.L., Javitt, N.B., Korach, K.S., Shaul, P.W. and Mangelsdorf, D.J., 2007. 27-Hydroxycholesterol is an endogenous SERM that inhibits the cardiovascular effects of estrogen, Nat Med. 13, 1185-92.

Vogel, V.G., Costantino, J.P., Wickerham, D.L., Cronin, W.M., Cecchini, R.S., Atkins, J.N., Bevers, T.B., Fehrenbacher, L., Pajon, E.R., Jr., Wade, J.L., 3rd et al., 2006. Effects of tamoxifen vs raloxifene on the risk of developing invasive breast cancer and other disease outcomes: the NSABP Study of Tamoxifen and Raloxifene (STAR) P-2 trial, JAMA. 295, 2727-41.

Vogel, V.G., Costantino, J.P., Wickerham, D.L., Cronin, W.M., Cecchini, R.S., Atkins, J.N., Bevers, T.B., Fehrenbacher, L., Pajon, E.R., Wade, J.L., 3rd et al., 2010. Update of the National Surgical Adjuvant Breast and Bowel Project Study of Tamoxifen and Raloxifene (STAR) P-2 Trial: Preventing breast cancer, Cancer Prev Res (Phila). 3, 696706.

Wakeling, A.E., Dukes, M. and Bowler, J., 1991. A potent specific pure antiestrogen with clinical potential, Cancer Res. 51, 3867-73. 
Walter, P., Green, S., Greene, G., Krust, A., Bornert, J.M., Jeltsch, J.M., Staub, A., Jensen, E., Scrace, G., Waterfield, M. et al., 1985. Cloning of the human estrogen receptor cDNA, Proc Natl Acad Sci U S A. 82, 7889-93.

Wardell, S.E., Nelson, E.R., Chao, C.A. and McDonnell, D.P., 2013. Bazedoxifene exhibits antiestrogenic activity in animal models of tamoxifen-resistant breast cancer: implications for treatment of advanced disease, Clin Cancer Res. 19, 2420-31.

Wolf, D.M. and Jordan, V.C., 1993. A laboratory model to explain the survival advantage observed in patients taking adjuvant tamoxifen therapy, Recent Results Cancer Res. 127, 23-33.

Wolf, D.M. and Jordan, V.C., 1994. The estrogen receptor from a tamoxifen stimulated MCF-7 tumor variant contains a point mutation in the ligand binding domain, Breast Cancer Res Treat. 31, 129-38.

Wu, A.H., Yu, M.C., Tseng, C.C. and Pike, M.C., 2008. Epidemiology of soy exposures and breast cancer risk, Br J Cancer. 98, 9-14.

Wu, Q., Ishikawa, T., Sirianni, R., Tang, H., McDonald, J.G., Yuhanna, I.S., Thompson, B., Girard, L., Mineo, C., Brekken, R.A. et al., 2013. 27-Hydroxycholesterol promotes cellautonomous, ER-positive breast cancer growth, Cell Rep. 5, 637-45.

Yang, J., Singleton, D.W., Shaughnessy, E.A. and Khan, S.A., 2008. The F-domain of estrogen receptor-alpha inhibits ligand induced receptor dimerization, Mol Cell Endocrinol. 295, 94-100.

Yao, K., Lee, E.S., Bentrem, D.J., England, G., Schafer, J.I., O'Regan, R.M. and Jordan, V.C., 2000. Antitumor action of physiological estradiol on tamoxifen-stimulated breast tumors grown in athymic mice, Clin Cancer Res. 6, 2028-36.

Yu, M., Bardia, A., Aceto, N., Bersani, F., Madden, M.W., Donaldson, M.C., Desai, R., Zhu, H., Comaills, V., Zheng, Z. et al., 2014. Cancer therapy. Ex vivo culture of circulating breast tumor cells for individualized testing of drug susceptibility, Science. 345, 216-20.

Ziel, H.K. and Finkle, W.D., 1975. Increased risk of endometrial carcinoma among users of conjugated estrogens, N Engl J Med. 293, 1167-70. 
Table 1

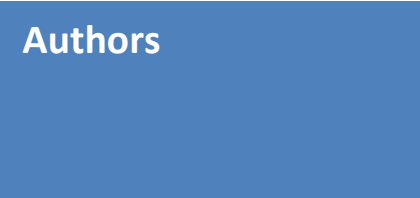

Li et al. 2013 Cell Reports

4:1116-1130

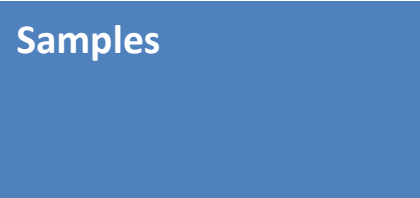

22 total

7 primary

15 mets. ( 2 from the same patient)

13 total

5 liver mets. 73:6856-6864.

\section{Toy et al. 2013}

Nature Genetics.

45:1439-1445.
183 primary

80 mets.

\section{Type of Mutation (\# of mutants)}

ESR1 YAP1 fusion (1)

Tyr537Ser (2)

Glu380GIn (1)
Percent

from total

mutations

25

50

25

100
Percent of total

samples

26.6

38
Asp538Gly (5)

Ser463Pro/Asp538Glu (1)
Ser463Pro/Tyr537Asn (1)
Val534Glu (1)
Pro535His (1)
Leu536Arg (1)
Tyr537Ser (4)
Tyr537Asn (1)
Tyr537Cys (1)
Asp538Gly (2)
Tyr537Ser/Asp538Gly (1)

7.1

7.1

7.1

7.1

7.1

28.6

7.1

7.1

14.3

7.1

33.33

33.33

33.33
$3.28 \%$ of total primary

$17.5 \%$ of total mets.
Yu et al. 2014

Science. 345:216-220.
6 patients with

Leu536Pro (1)

circulatin
Tyr537Ser (1)

Asp538Gly (1)
16.7

50

33.3

9.1

9.1

18.2

27.3

18.2

18.2

14.5

54.5

Asp538Gly (2)

Asp538Gly (3)

Tyr537Ser (2)

Tyr537Cys (2) 


\section{Table legend}

Table 1. A compilation of ESR1 mutations observed in breast cancer metastases published in 6 recent studies. The role of these mutations has been discussed in a recent review by Jordan et al (Jordan et al., 2015). 


\section{Figure legends}

Figure 1. Chemical structures of 17ß-estradiol $\left(\mathrm{E}_{2}\right)$, 4-hydroxytamoxifen (4OHT) and raloxifene. Estradiol is a natural planar estrogen, that initiates an agonist conformation of the Ligand Binding Domain of the ER. Raloxifene and 4OHT are both FDA approved SERMs for the treatment and prevention of ER-positive breast cancer in high risk women and the treatment of osteoporosis (raloxifene).

Figure 2. Schematic structure of the estrogen receptor (ER) depicting six domains. The $\mathrm{E}$ domain is the Ligand Binding Domain (LBD) and binds both estrogens and antiestrogens. Amino acids 351,537 and 538 are functionally important to complete the folding of the ER and interact with each other (Toy et al., 2013), and also are sites for point mutations in metastatic breast cancer (Table 1) (537 and 538) or acquired resistance to tamoxifen (Wolf and Jordan, 1994).

Figure 3. The conformation of the Ligand Binding Domain (LBD) of the ER regulates the activity of the receptor. The shape of the ER's LBD governs the recruitment of either CoAs or CoRs and thereby expressing a variety of responses in target tissues, such as estrogenic or antiestrogenic actions. Abbreviations: CoA, co-activator; CoAc, co-activator complex; CoCo, co-co-activator; CoR, co-repressor; ER, oestrogen receptor; ERC, oestrogen receptor complex; SERM, selective oestrogen-receptor modulator. Permission obtained from Nature Publishing Group ( $)$ (Jordan, 2007)

Figure 4. Molecular modelling of interaction of different ligands with the Ligand Binding Domain (LBD) of the ER. A: localization and interaction of $17 \beta$-estradiol $\left(\mathrm{E}_{2}\right)$ with amino acids in the LBD, based on the X-ray crystallography; B: The localization of amino acids Asp351, Tyr537 and Asp538 on the surface of the $\mathrm{E}_{2}$ :ER complex; C: The localization of raloxifene in the LBD of the ER based on the X-ray crystallography, and the ligand's piperidine ring interaction and neutralization of Asp351; D: localization of 4OHT in the LBD of the ER based on X-ray crystallography, where 4OHT's side chain is located further away from Asp351 than with raloxifene. Permission for reuse of images from Jordan et al., 2015 was obtained from the Oxford University Press.

Figure 5. The evolution of antiestrogen resistance in breast cancer models. Phase I resistant disease grows with either SERMs or estrogen. Phase II resistance is characterized by SERMstimulated growth and inhibition by estrogen, and phase III resistance is characterized by autonomous growth of ER-positive antiestrogen resistant breast cancer cells that are killed by estrogens via apoptosis.

Figure 6. Gene expression array of apoptosis-associated genes in long-term estrogen deprived cells. Expression of the proapoptotic genes is activated by estradiol and inhibited by 4hydroxytamoxifen (4OHT) (Fan et al., 2013,Sweeney et al., 2014a). 
Figure 7. Alternative altered functions of the ER in SERM resistant breast cancer cells, in particular the activation of membrane-associated molecules, such as adhesion and adapter proteins and IGF-1R $\beta$ growth factor receptor. Estrogen $\left(\mathrm{E}_{2}\right)$ activates both nuclear ER and membrane-associated ER. Tamoxifen (TAM) consistently suppresses nuclear ER, but activates membrane-associated ER and related molecules to stimulate cell growth.

Figure 8. The results of microarray data analysis (Ariazi et al., 2011) of expression levels of inflammatory pathway genes after treatment of breast cancer cell lines with different phenotypes. The MCF-7:WS8 cells are cells with wild-type phenotype that respond to estrogen treatment with cell proliferation; MCF-7:5C and MCF-7:2A cells are cell lines that are antiestrogen resistant, grow autonomously in estrogen-free conditions and respond to estrogen treatment with apoptosis. However, MCF-7:2A cells have a delayed apoptotic response compared to MCF-7:5C cells. The figure shows in each panel a different inflammation associated gene, where expression levels are elevated with estrogen treatment in MCF-7:5C cells, indicating a clear involvement of inflammatory pathway in the estrogen-induced apoptosis in these breast cancer cells. (Ariazi, E.A., Cunliffe, H.E., Lewis-Wambi, J.S., Slifker, M.J., Willis, A.L., Ramos, P., Tapia, C., Kim, H.R., Yerrum, S., Sharma, C.G. et al., 2011. Estrogen induces apoptosis in estrogen deprivationresistant breast cancer through stress responses as identified by global gene expression across time, Proc Natl Acad Sci U S A. 108, 18879-86.) 
FIGURES

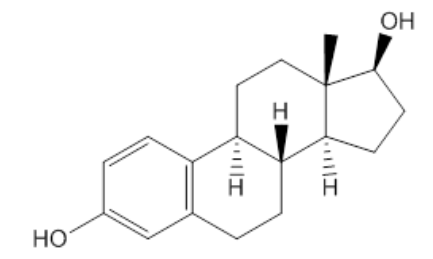

17ß-estradiol (E2)

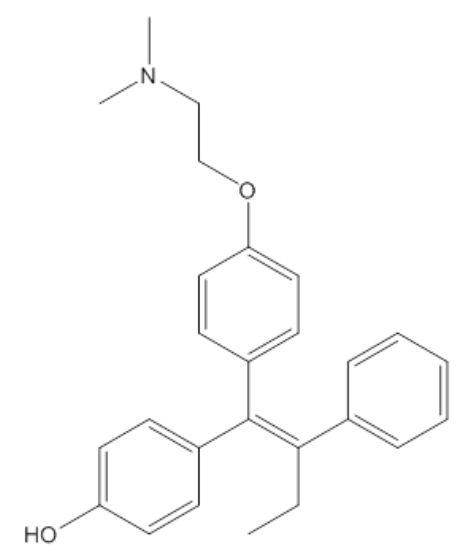

4-hydroxytamoxifen (4OHT)

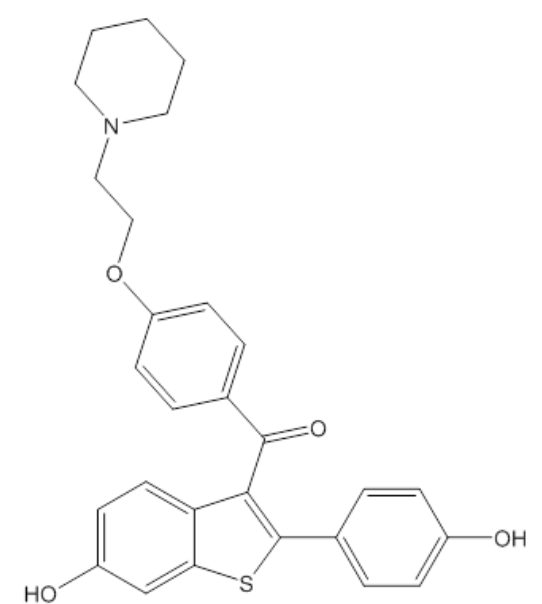

Raloxifene

Figure 1 


\section{Ligand Binding Domain}

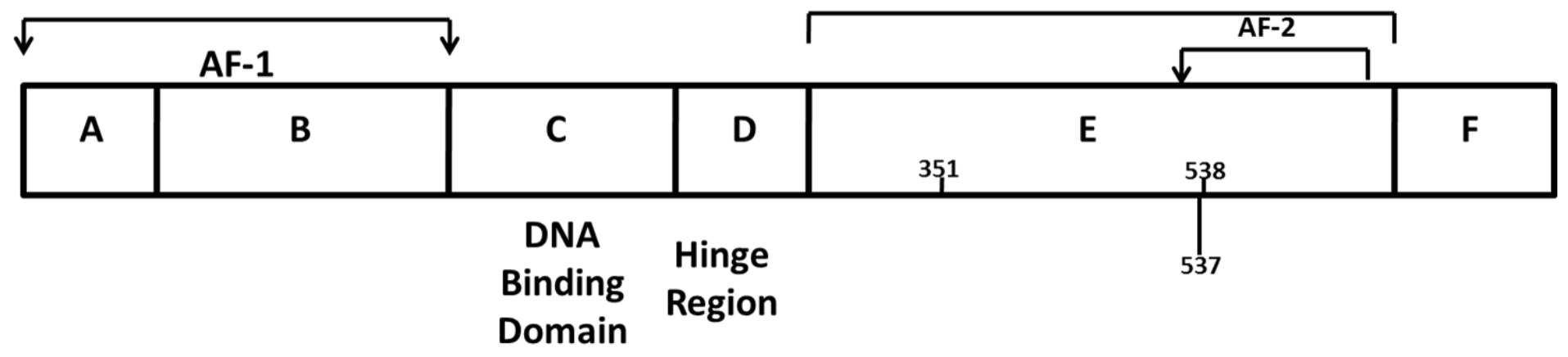

Figure 2 


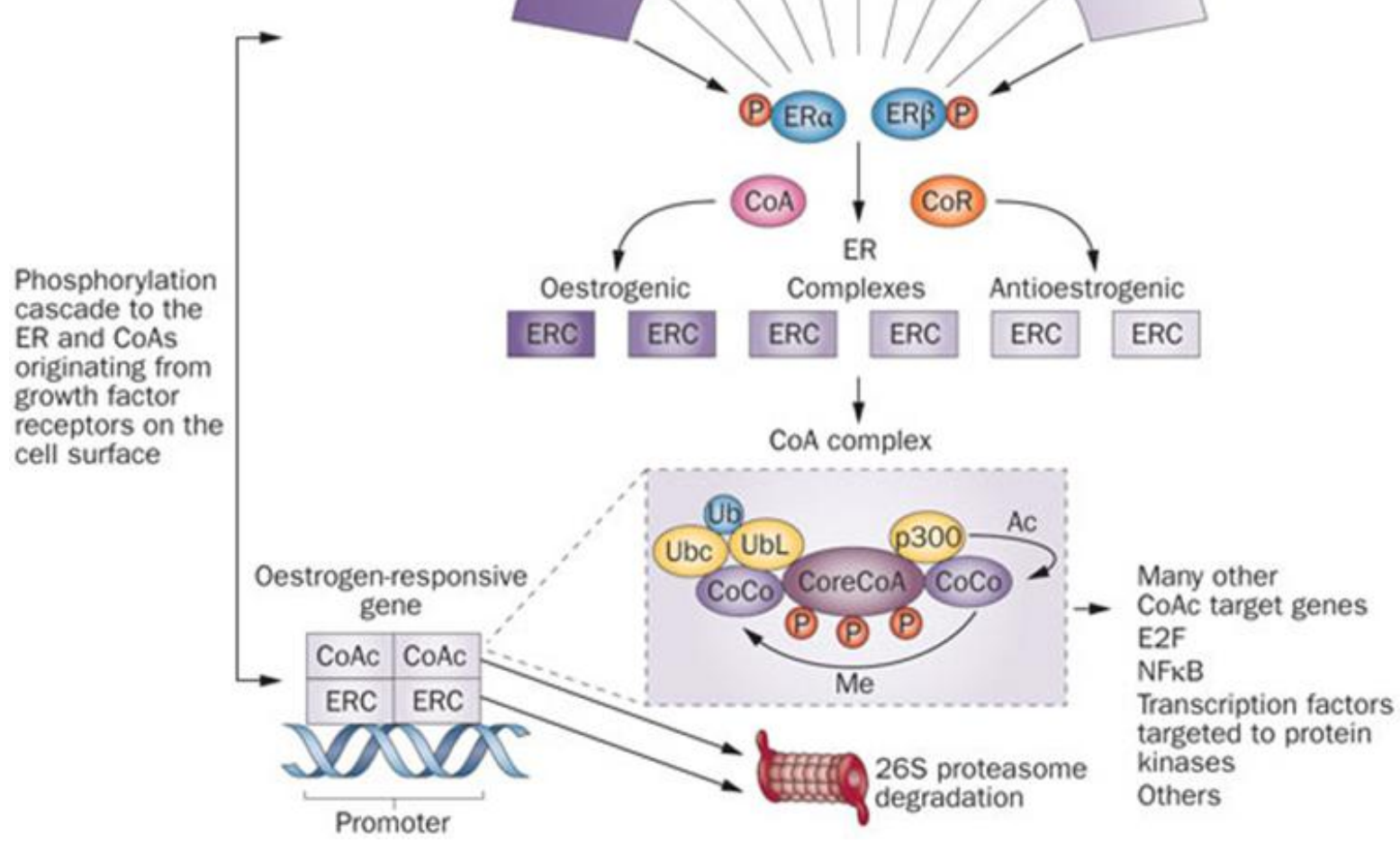

Figure 3 


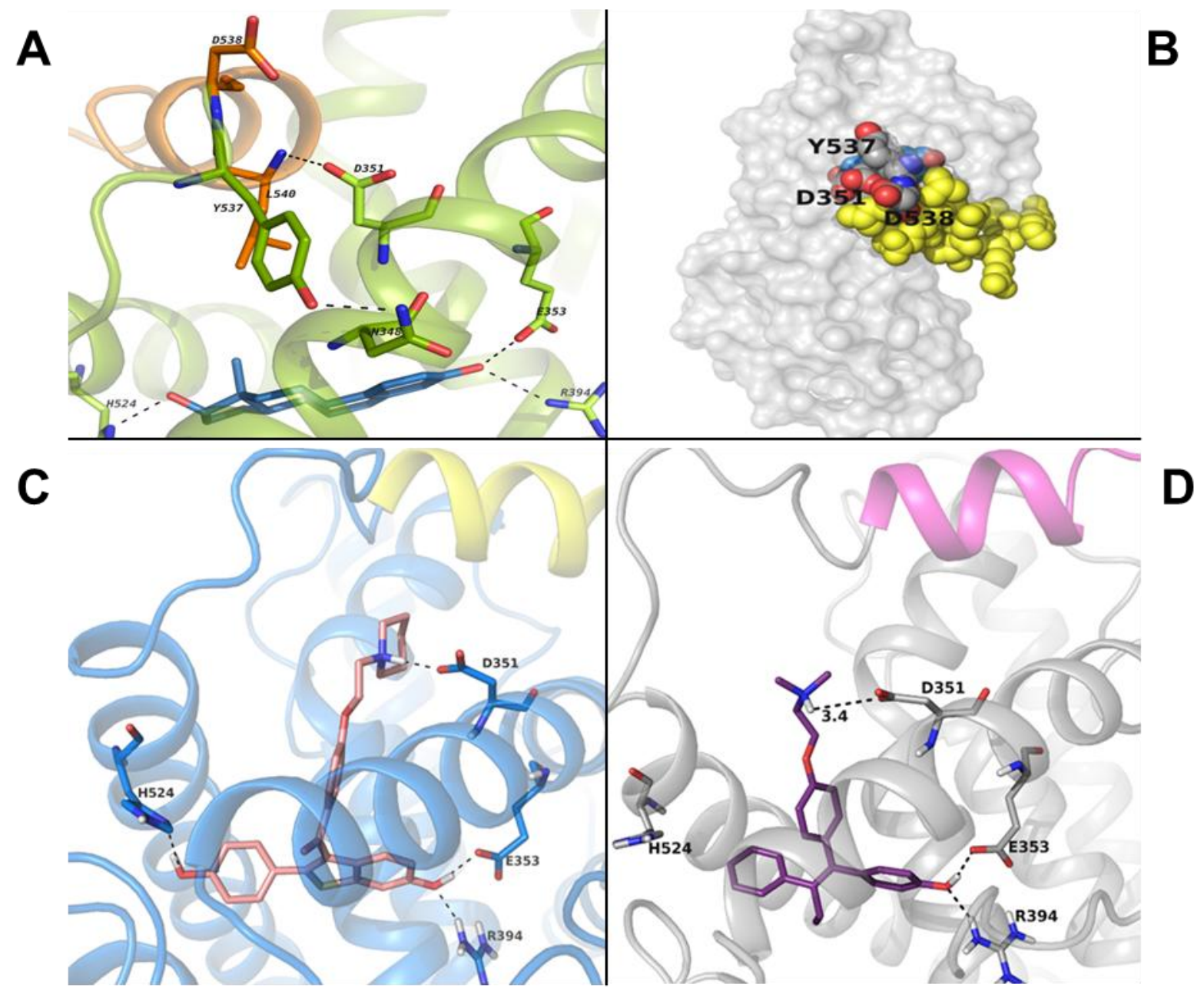

Figure 4 


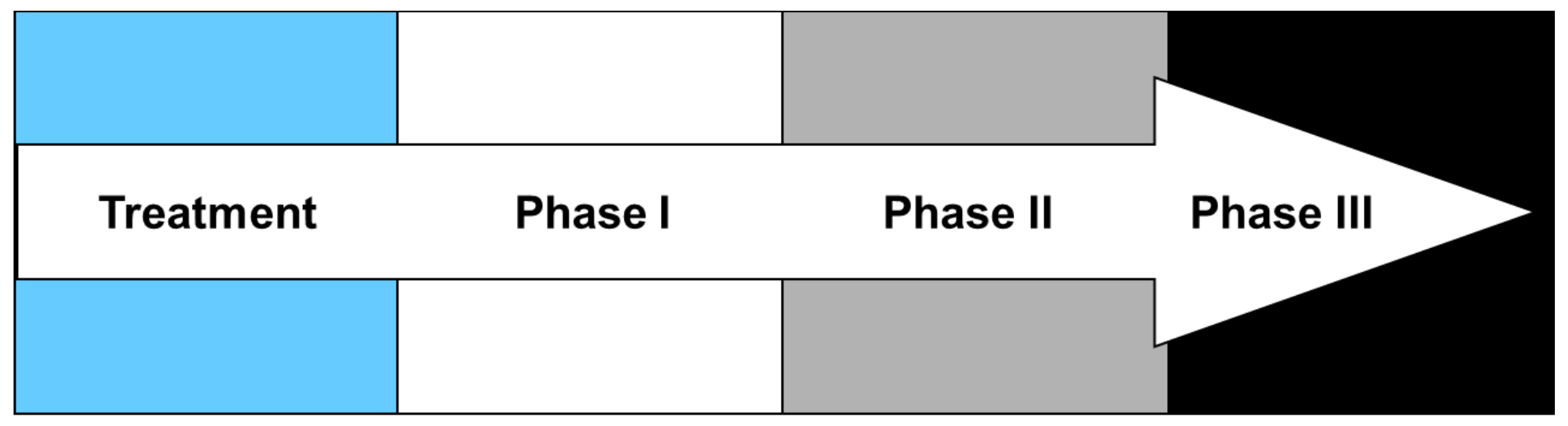
Antiestrogen
$E_{2}$ or
SERM- action of
SERM-
stimulated
SERMs
stimulated
$E_{2}$ Inhibited

\section{Current Clinical applications}

\section{Future Clinical applications}

Autonomous

growth

$E_{2}$ Inhibited

Figure 5 


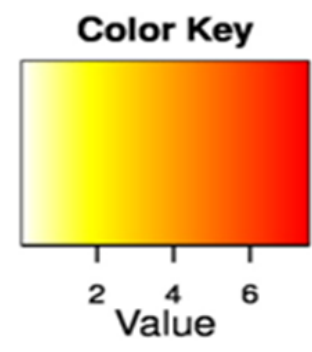

\section{Cufflinks gene-level expression}
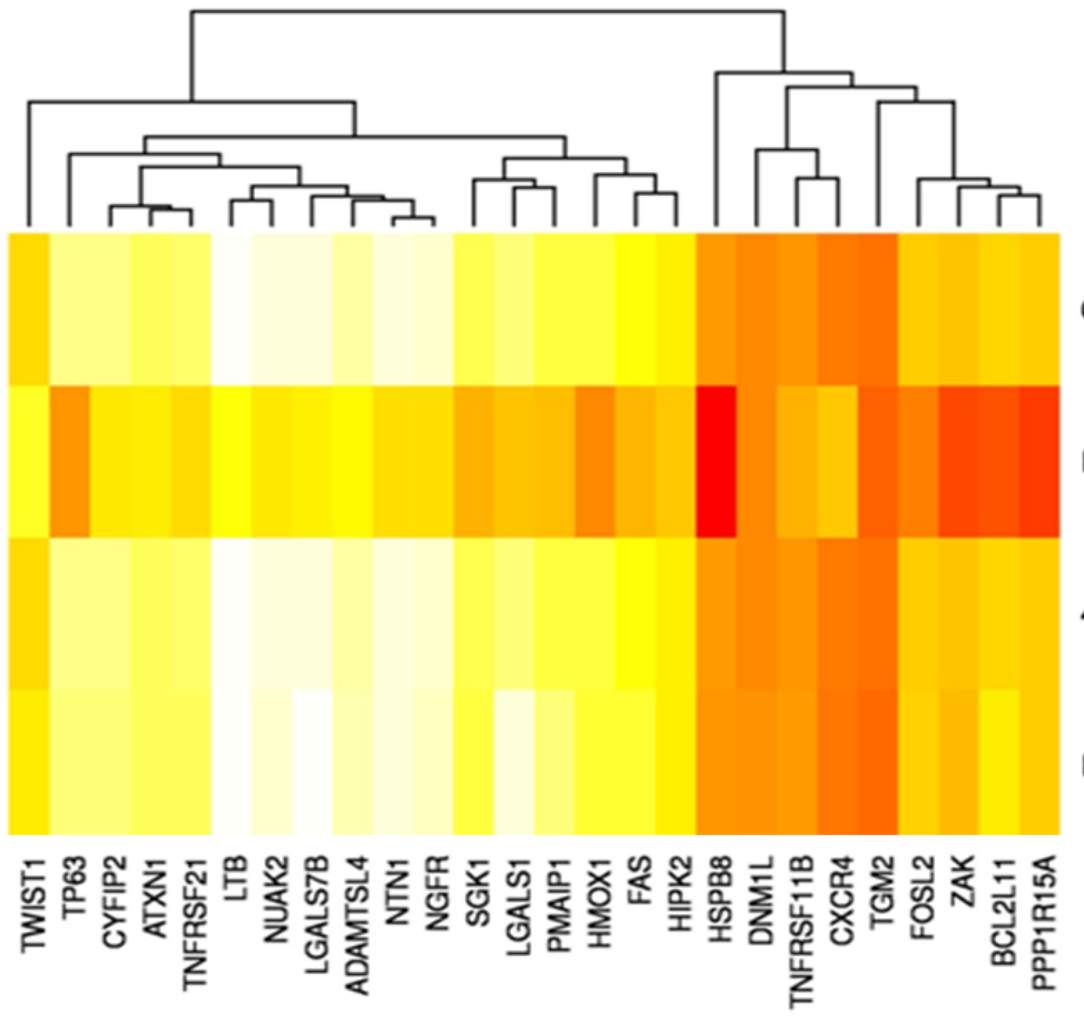

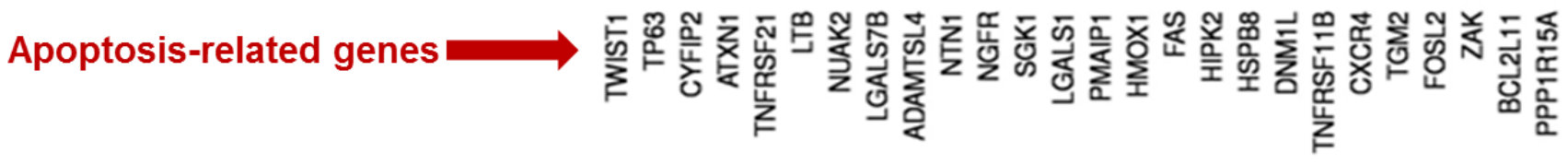

Control

E2

$40 \mathrm{HT}$

$\mathrm{E} 2+4 \mathrm{OHT}$

Figure 6 


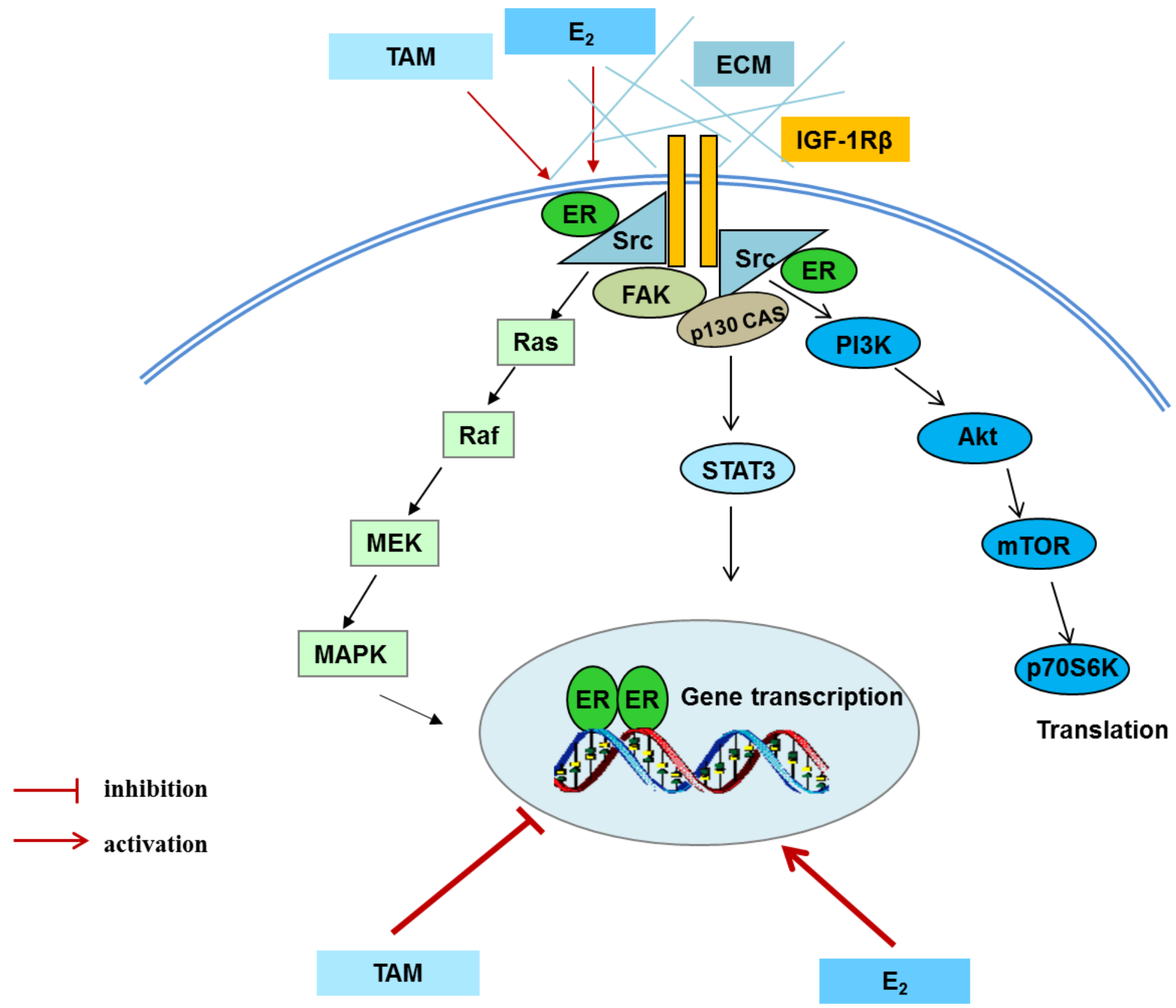

Figure 7 


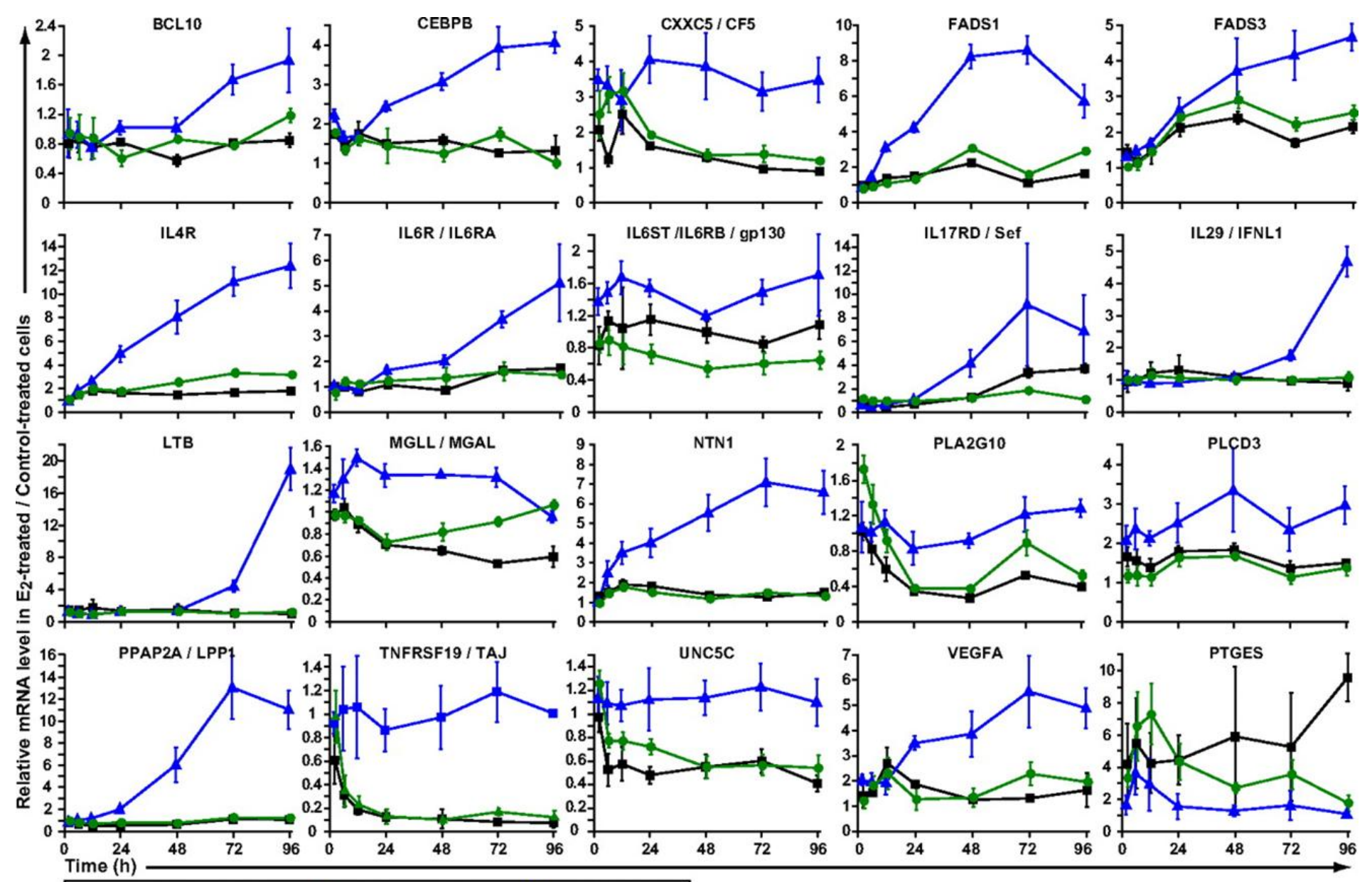

-MCF-7:WS8 - MCF-7:2A $\rightarrow$ MCF-7:5C

Figure 8 